ESTUDO COMPARATIVO ENTRE ECOENDOSCOPIA E ENDOSCOPIA DIGESTIVA ALTA NO DIAGNÓSTICO DOS TUMORES SUBEPITELIAIS DO ESÔFAGO ESTÔMAGO E DUODENO

Dissertação apresentada à Faculdade de Medicina de Ribeirão Preto da Universidade de São Paulo para obtenção do Título de Mestre em Medicina

Orientador: Prof. Dr. Reginaldo Ceneviva Co-Orientador: Dr. José Celso Ardengh 
AUTORIZO A REPRODUÇÃO E DIVULGAÇÃO TOTAL OU PARCIAL DESTE TRABALHO, POR QUALQUER MEIO CONVENCIONAL OU ELETRÔNICO, PARA FINS DE ESTUDO E PESQUISA, DESDE QUE CITADA A FONTE

\section{Vaiciunas, Spencer}

ESTUDO COMPARATIVO ENTRE ECOENDOSCOPIA E ENDOSCOPIA DIGESTIVA ALTA NO DIAGNÓSTICO DOS TUMORES SUBEPITELIAIS DO ESÔFAGO, ESTÔMAGO E DUODENO/ Spencer Vaiciunas; Orientador Prof. Dr. Reginaldo Ceneviva -- Ribeirão Preto, 2008. xii, 56 f.

Dissertação (Mestrado - Programa de Pós-graduação em Medicina: Área de Concentração: Clínica Cirúrgica). Faculdade de Medicina de Ribeirão Preto da Universidade de São Paulo

1. Tumor subepitelial 2. Ecoendoscopia 3. Endoscopia digestiva alta 
ESTUDO COMPARATIVO ENTRE ECOENDOSCOPIA E ENDOSCOPIA DIGESTIVA ALTA NO DIAGNÓSTICO DOS TUMORES SUBEPITELIAIS DO ESÔFAGO ESTÔMAGO E DUODENO

Dissertação apresentada à Faculdade de Medicina de Ribeirão Preto da Universidade de São Paulo para obtenção do Título de Mestre em Medicina

Aprovada em:

BANCA EXAMINADORA

Prof. Dr.

Instituição Assinatura

Prof. Dr.

Instituição Assinatura

Prof. Dr.

Instituição Assinatura 


\section{DEDICATÓRIA}

Dedico este trabalho a todas as pessoas que contribuíram para a minha formação médica, em especial aos meus pais, Mauricio Casimiro Vaiciunas e Sueli Maria dos Santos Vaiciunas, por estarem sempre ao meu lado, pelo apoio, amor, carinho e amizade.

À Karla Nocrato Loiola Vaiciunas pelo amor, respeito e cumplicidade. 


\section{AgRadecimentos}

Ao Prof. Dr. Reginaldo Ceneviva, orientador, pela amizade, apoio e ensinamentos que me proporcionou durante este curso de pós-graduação. Pela oportunidade e incentivo na concretização deste trabalho.

Ao Prof. Dr. José Celso Ardengh, endoscopista do Hospital 9 de Julho, pelo apoio e gentileza em compartilhar, de forma, irrestrita, dados de seus pacientes, que foram imprescindíveis para a realização deste trabalho.

Ao Prof. Dr. José Luis Pimenta Módena, chefe do Setor de Endoscopia Digestiva da FMRPUSP, pelo incentivo à minha iniciação científica e pelos ensinamentos na área de endoscopia digestiva.

Ao Prof. Dr. Artur Adolfo Parada, chefe do Setor de Endoscopia Digestiva e Ecoendoscopia do Hospital 9 de Julho, pela oportunidade de realizar este trabalho.

Aos meus pais, que tanto lutaram para me proporcionar o melhor, que abdicaram de momentos seus sempre com o intuito de auxiliar minha caminhada rumo ao crescimento profissional e pessoal.

À querida esposa Karla Nocrato Loiola Vaiciunas, pelo amor e compreensão durante minha ausência na elaboração deste trabalho e apoio incondicional em todos os momentos da minha vida. 


\section{RESUMO}

A descoberta endoscópica de um tumor subepitelial (TSE) é freqüente. Geralmente o aspecto corresponde à de uma compressão extrínseca $(\mathrm{CE})$ ou ao de um tumor intramural (TI). O diagnóstico dessas lesões, por vezes, é difícil, mesmo após a obtenção de biópsias pela endoscopia digestiva alta (EDA). A ecoendoscopia (EE) tem apresentado importante papel na elucidação diagnóstica. A proposta nesse estudo foi comparar os resultados da EDA com os da EE no diagnóstico diferencial entre TI e CE do esôfago, estômago e duodeno e avaliar o desempenho da ecoendoscopia no diagnóstico diferencial dos TSE. Foi feita análise retrospectiva dos exames de 176 pacientes (93 mulheres), com média de idade de 62,5 (10 89) anos, de janeiro de 2000 a maio de 2006, que foram estudados por EDA e EE por apresentar abaulamento subepitelial ao exame endoscópico do trato gastrointestinal alto. $\mathrm{O}$ tamanho, mobilidade, localização e o diagnóstico de presunção foram registrados no momento da EDA. Durante a EE foram analisados o tamanho, a ecogenicidade do tumor, as camadas da parede da víscera e o diagnóstico presuntivo. Todos os pacientes foram avaliados consecutivamente pela EDA e EE. Os tumores intramurais representaram $87 \%$ dos casos e dentre eles, o tumor estromal gastrointestinal foi a maioria (62\%), enquanto as compressões extrínsecas representaram 13\%, das quais a compressão pelo fígado foi a mais frequente (31\%). Para a avaliação dos TI a sensibilidade, especificidade a acurácia da EDA foram menores de $50 \%$ com p=0,25 e para a EE de 95\%, $100 \%$ e $95 \%$ respectivamente, com p=0,0003 (teste de Fisher). Na avaliação das CE, a sensibilidade, especificidade e acurácia da EDA foram de $87 \%, 50 \%$ e $86 \%$ com p=0,43 e a $\mathrm{EE}$ de $95 \%, 100 \%$ e $95 \%$ respectivamente, com $\mathrm{p}=0,08$ (teste de Fisher). Conclui-se que a endoscopia digestiva é um bom exame para diagnosticar a presença de tumores intramurais do trato digestivo, mas tem fraco desempenho em identificar o tipo específico do tumor, e é um mau exame para o diagnóstico das compressões extrínsecas. Por outro lado, a ecoendoscopia é um bom exame para o diagnóstico diferencial dos tumores subepiteliais, podendo fornecer com precisão a localização do tumor além de permitir biópsias dirigidas. 


\begin{abstract}
The endoscopic view of a subepithelial lesion (SL) lesion is usual. This may corresponds to an extramural compression (EC) or an intramural lesion (IL). The diagnosis of these lesions, sometimes becomes difficult, even after biopsies which usually do not contribute for it. The endoscopic ultrasonography has an important role in the diagnosis briefing. The aim of this study was to compare the results of EGD (esophagogastroduodenoscopy) with the EUS (endoscopic ultrasonography) in the differential diagnosis between SL and EC of the upper gastrointestinal tract and the EUS role in the differential diagnosis of a SL. A retrospective analysis was performed in 176 patient's records, (93 women), with average of age of 62,5 (10 89) years, from january 2000 up to may 2006, that underwent to EGD and EUS due to SL in the digestive tract. The size, localization and the presumptive diagnosis were registered at the moment of the EGD. During the EUS, size, echogenecity and a presumptive diagnosis were analyzed. All the patients were evaluated consecutively by EGD and EUS. The intramurals tumors represented $87 \%$ of the cases and amongst them; gastrointestinal tumors were the majority (62\%), while the extramural compressions represented $13 \%$, and a liver compression in $31 \%$. The agreement of EGD and USE by Kappa's method for the presumptive diagnosis of the subepithelials lesions was very poor $(\kappa=0,15)$ in intramurals lesions and inadequate $(\kappa<0,00)$ for the EC. Sensitivity, specificity and accuracy of the EGD were lower than 50\% $\mathrm{p}=0,25$ and for USE $95 \%, 100 \%$ and $95 \%$ respectively, and $\mathrm{p}=0,0003$ (Fisher's test) In the evaluation of the EC, sensitivity, specificity and accuracy of EGD were $87 \%, 50 \%$ and $86 \%$ $\mathrm{p}=0,43$ and for USE 95\%, 100\% and 95\% respectively, and $\mathrm{p}=0,08$ (Fisher's test). The conclusion is that EGD presents high sensitivity and accuracy and a low specificity to identify intramural tumors and in the EC, all these parameters are low. So it's a good exam to make the diagnosis of a intramural lesion but it's poor to identify the kind of lesion and extramural compressions. On the other hand, the USE presents high sensitivity, specificity and accuracy in all kinds of SL, also making possible a precision diagnosis of the lesion's layer, allowing to distinguish the lesions and also to get histological samples.
\end{abstract}




\section{LISTA DE ILUSTRAÇÕES}

Quadro 1: Consenso sobre a indicação da EE no estudo do TSE baseado no conceito de adequação

Quadro 2: Relação entre as camadas comprometidas, a etiologia mais freqüente e a aparência dos TSE à EE

Figura 1: Aspecto ecográfico com sonda de 7,5 MHz demonstrando as cinco camadas descritas.

Figura 2: Distribuição das indicações da EDA inicial..................................... 24

Figura 3: Distribuição quanto aos tipos de tumores subepiteliais...................... 25

Figura 4: Imagem endoscópica de abaulamento da parede do terço proximal 25 gástrico.

Figura 5: $\quad$ Distribuição quanto às causas de compressão extrínseca................... 26

Figura 6: A. Imagem endoscópica de TSE B. Imagem ecoendoscópica de um 26 leiomioma.

Figura 7: Distribuição quanto aos tipos de lesões intramurais

Figura 8: Distribuição dos tumores intramurais de acordo com a camada de origem.

Figura 9: Distribuição dos tumores intramurais nas diferentes porções dos órgãos.

Figura 10: Imagem endoscópica e ecoendoscópica de TEGI.....

Figura 11: Imagem ecoendoscópica de tumor nodular de TEGI confirmado pela histologia da peça cirúrgica.

Figura 12: Imagem endoscópica de um leiomioma.

Figura 13: Imagem endoscópica de um leiomioma esofagiano.

Figura 14: Imagens endoscópicas de lipoma................................................ 30

Figura 15: Imagem ecoendoscópica do mesmo lipoma da figura $14 \ldots \ldots \ldots \ldots \ldots \ldots . . . . . .31$

Figura 16: A. Imagens endoscópica B. Imagem ecoendoscópica de varizes de fundo gástrico.

Figura 17: A. Imagem endoscópica de varizes de fundo gástrico B. imagem ecoendoscópica com estruturas vasculares pérvias e sinal de Doppler positivo.

Figura 18: A. Imagem endoscópica e ecoendoscópica de cisto B. Nódulo hipoecóico gástrico arredondado e de pequenas proporções............. 32

Figura 19: Imagem endoscópica de tumor de Abrikossof................................. 33 


\section{LISTA DE TABELAS}

Tabela 1: Valores do índice Kappa obtidos no estudo da concordância da interpretação ecoendoscópica sem Doppler dos TSE ..................... 04

Tabela 2: Correlação anatômica entre o sítio anatômico do TGI onde as CE são visualizadas e os possíveis órgãos responsáveis por elas... 08

Tabela 3: $\quad$ EDA x Histologia no Diagnóstico de Compressão Extrínseca....... 34

Tabela 4: $\quad$ EE x Histologia no Diagnóstico de Compressão Extrínseca.......... 34

Tabela 5: $\quad$ EDA x Histologia no Diagnóstico de Tumor Intramural................ 35

Tabela 6: $\quad$ EE x Histologia no Diagnóstico de Tumor Intramural.................. 35 


\section{LiSTa de Abreviaturas e Símbolos}

$\begin{array}{ll}\text { \% } & \text { Porcentagem } \\ < & \text { Menor } \\ \mathbf{\kappa} & \text { Kappa } \\ \mathbf{c m} & \text { Centímetro }\end{array}$

TGI Trato gastrointestinal

TSE Tumor subepitelial

CE Compressão extrínseca

TEGI Tumor estromal gastrointestinal

EDA Endoscopia digestiva alta

EE Ecoendoscopia

EE-PAAF Punção aspirativa com agulha fina guiada por ecoendoscopia

TC Tomografia computadorizada

RM Ressonância magnética

TI Tumor intramural 
SUMÁRIO

Resumo

Abstract

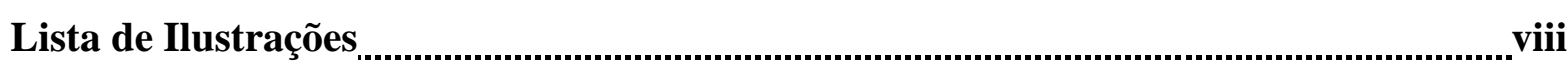

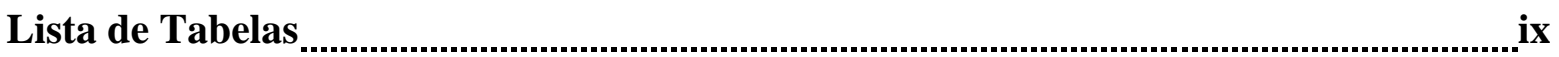

Lista de Abreviaturas

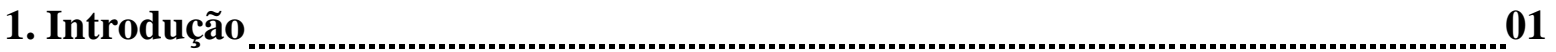

2. Objetivos

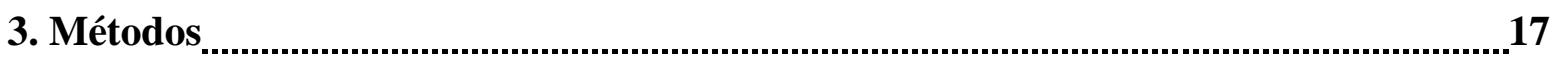

3.1 Local e modelo de estudo $\ldots$

3.2 Critérios de inclusão

3.3 Critérios de exclusão

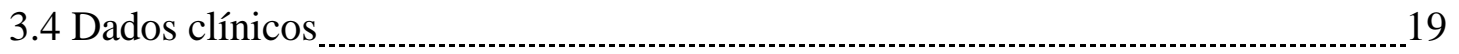

3.5 Exame endoscópico

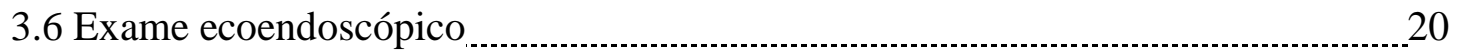

3.7 Exame histológico $\ldots \ldots \ldots \ldots \ldots \ldots \ldots$

3.8 Aspectos éticos

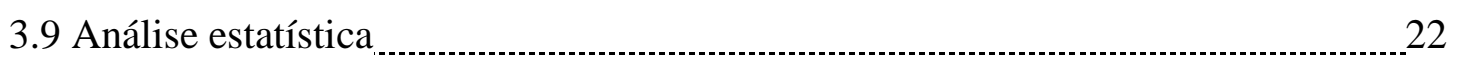

4. Resultados

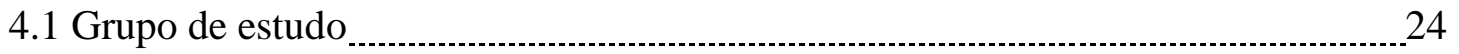

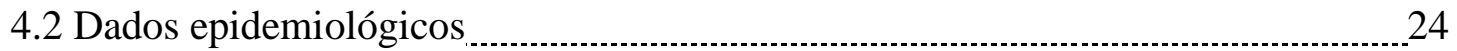

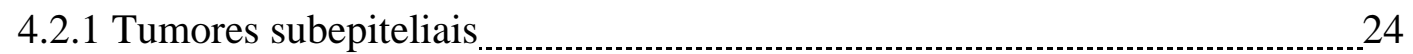

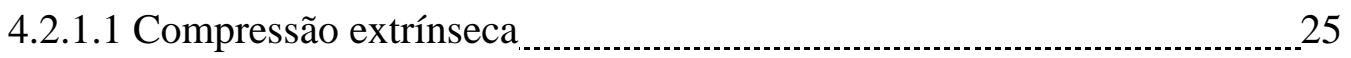

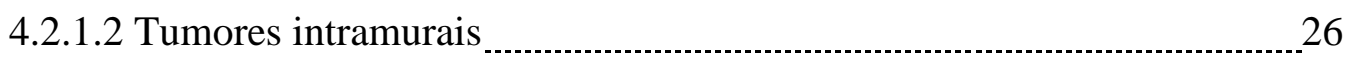

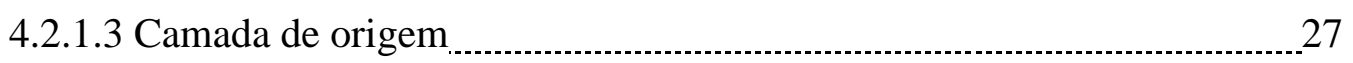

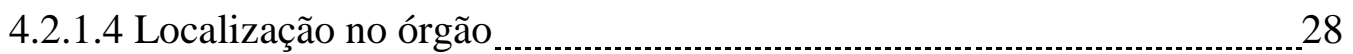

4.3 Avaliação endoscópica e ecoendoscópica dos tumores intramurais _...................... 28

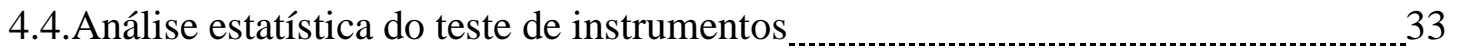

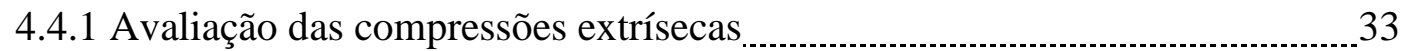

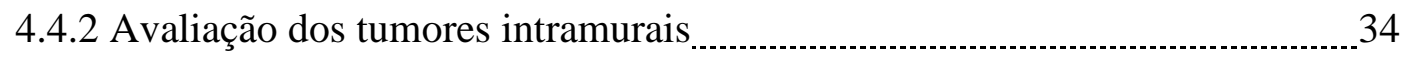

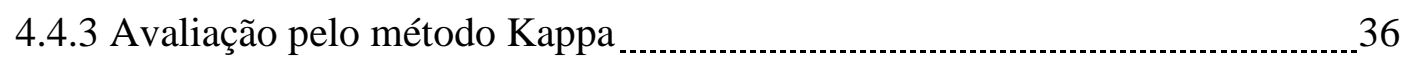

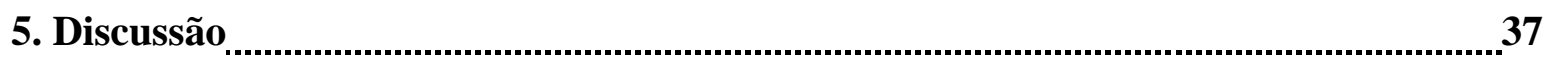

6. Conclusão

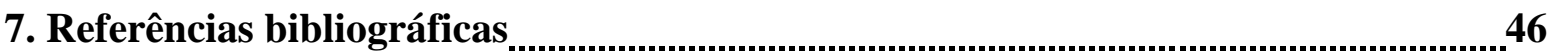


INTRODUÇÃO 


\section{INTRODUÇÃO}

Os médicos lidam, em determinados momentos, com pacientes com alterações anatômicas no trato gastrointestinal (TGI) de significado questionável. Por definição, as lesões circunscritas de base larga ou pediculadas, que se projetam da superfície mucosa para o interior do lúmen do TGI sem etiologia definida pela avaliação endoscópica ou pelo exame contrastado são chamadas de "lesões elevadas ou submucosas". No entanto, este termo expressa incorretamente lesões classificadas nesta categoria porque elas necessariamente não têm sua origem ou estão restritas apenas à camada submucosa, devendo, portanto serem nomeadas como "subepiteliais" (TSE). Em geral, são achados incidentais do exame endoscópico ou radiológico, sem apresentar relação causal com a queixa que motivou a investigação do paciente, estando nas considerações diagnósticas uma variedade de tumores intramurais ou ainda compressões causadas por estruturas extrínsecas (CE), fato que destaca a importância da condução ponderada dessa situação, não infreqüente na prática endoscópica ${ }^{1-4}$.

O TSE ocorre de forma uniforme entre homens e mulheres havendo predomínio após a $5^{\mathrm{a}}$ década de vida, sendo os pacientes, em sua maioria, assintomáticos ${ }^{5}$; eventualmente podem apresentar sintomas obstrutivos e anemia; ocasionada pelo sangramento gastrintestinal secundário à ulceração superficial da lesão e que resulta da relação discrepante entre seu tamanho e seu suprimento sanguíneo. O surgimento de dor, perda de peso e o aumento do tamanho da lesão podem sugerir malignidade ${ }^{4}$.

À radiografia contrastada estas lesões são visualizadas na maioria dos casos como deformidades endoluminais com contornos regulares. Sua avaliação endoscópica prende-se ao aspecto geral, tamanho, forma, consistência, cor, prega em ponte, sinal da tenda, etc.

Esses dados permitem no máximo o diagnóstico de suposição, porque a superfície mucosa é habitualmente típica e a biópsia convencional é freqüentemente normal ${ }^{4}$. 
Vários tipos de lesões como tumor estromal gastrintestinal (TEGI), leiomioma, lipoma e tumor metastático podem apresentar-se como TSE. As varizes esofagianas, gástricas ou retais, cisto de duplicação, pâncreas ectópico, esplenomegalia, vesícula biliar e outras estruturas podem simular TSE. Algumas destas entidades apresentam aspecto ecográfico típico, por exemplo, os lipomas que são visualizados como massas hiperecóicas situadas na terceira camada do tubo digestivo ${ }^{6}$.

A indicação da ecoendoscopia (EE) para o diagnóstico diferencial de um TSE é atualmente considerada essencial e $\operatorname{segura}^{6-8}$ para a decisão terapêutica mais adequada (observação ou remoção), pois permite o estudo ecográfico detalhado da parede do tubo digestivo. O quadro 1 mostra o consenso sobre a indicação da EE no estudo dos TSE baseado no conceito de adequação. Seu uso foi corroborado por Gress e col. em um estudo sobre a concordância (índice de Kappa) da interpretação das imagens por diferentes profissionais que se mostrou excelente ou boa para o diagnóstico de CE, cistos e lipoma (Tabela 1) ${ }^{9}$.

Quadro 1: Consenso sobre a indicação da EE no estudo do TSE baseado no conceito de adequação $0^{10}$

Motivo para realizar a EE

Conceito de adequação*

Avaliação do padrão endoscópico do TSE no

estômago e esôfago

Complemento à endoscopia convencional durante o

seguimento dos TSE esofagianos não-ressecados

Complemento à endoscopia convencional durante $\mathrm{o}$

seguimento dos TSE gástricos não-ressecados

8

Diagnóstico diferencial entre TEGI maligno e benigno

6

Conceito de adequação: 1 a 3 - não indicada; 4 a 6 - indicação inconsistente; 7 - indicação apropriada, mas nem sempre necessária; 8 e 9 - indicação apropriada e necessária. 
Tabela 1: Valores do índice Kappa obtidos no estudo da concordância da interpretação ecoendoscópica sem Doppler dos TSE ${ }^{9}$.

\begin{tabular}{lccc}
\hline \multicolumn{1}{c}{ Tipo de lesão } & n & Valor Kappa & Classificação* \\
\hline Compressão extrínseca & 2 & 0,94 & Excelente \\
Cistos & 2 & 0,80 & Excelente \\
Leiomioma & 4 & 0,53 & Fraca \\
Estrutura vascular & 4 & 0,54 & Fraca \\
Lipoma & 4 & 0,65 & Boa \\
Outras lesões subepiteliais & 4 & 0,34 & Muito fraca \\
\hline $\begin{array}{l}\text { Classificação de concordância segundo os valores de Kappa: > } 0,80-\text { excelente; } 0,60 \text { a } 0,79-\text { boa; } 0,40 \text { a } \\
0,59 \text { - fraca, }<0,40 \text { - muito fraca. }\end{array}$
\end{tabular}

\section{CONCEITOS, PRINCÍPIOS E TÉCNICAS EM ECOENDOSCOPIA}

A ecoendoscopia, também conhecida como ultra-sonografia endoscópica ou endossonografia, permite conduzir um transdutor ecográfico a todos os pontos acessíveis ao endoscópio clássico. A EE combinada com transdutores, que podem ser de alta frequiência, favorece a obtenção de imagens de alta resolução, tornando possível o exame pormenorizado de órgãos e regiões pouco acessíveis a outros métodos de imagem. Além disso, permite o estudo detalhado das camadas da parede do esôfago, estômago e duodeno, o que não é possível com a endoscopia digestiva convencional, tomografia computadorizada (TC) ou ressonância magnética $(\mathrm{RM})^{11}$. A ecoendoscopia é um importante instrumento para o diagnóstico e tratamento em diversas situações clínicas, principalmente no estudo das lesões de submucosa, dos tumores de esôfago e das neoplasias precoces do estômago ${ }^{12}$.

As indicações da EE podem ser tanto diagnósticas (estadiamento e seguimento de neoplasias de mediastino, pulmão, vias biliares, pâncreas, esôfago, estômago, duodeno, cólon e reto), como terapêuticas (drenagem de pseudocistos de pâncreas, punção e/ou drenagem de abscessos mediastinais ou abdominais, etc) ${ }^{13}$. 
As contra-indicações podem ser absolutas (paciente não cooperativo, suspeita de perfuração visceral, diverticulite ou colite aguda) ou relativas (inexperiência do ecoendoscopista, estenose esofágica e instabilidade cardíaca ou pulmonar) ${ }^{13}$.

Existem dois métodos de escaneamento (transdutores): o radial (corte transversal ao eixo do aparelho) e o linear (corte longitudinal ao aparelho). Os transdutores radiais possibilitam a obtenção de imagens em 360 graus, em tempo real, o que facilita a avaliação das características anatômicas e patológicas das estruturas analisadas e os lineares auxiliam principalmente nos casos de punções guiadas ${ }^{14}$

Os transdutores apresentam freqüências que variam de 7,5 a $12 \mathrm{MHz}$. Esta variação de freqüência permite o controle da profundidade das imagens obtidas ${ }^{14}$.

O estudo com a ecoendoscopia depende da relação entre a penetração do feixe sonoro (que é maior quanto menor é a frequiência do transdutor) e a capacidade de resolução da imagem (que é maior quanto maior é a frequiência do transdutor). Com as frequiências maiores perde-se o poder de penetração do som, dificultando a avaliação de estruturas distantes, porém obtém-se maior resolução das imagens obtidas próximas do transdutor ${ }^{14}$.

Dois tipos de instrumentos são empregados: um utiliza o transdutor montado na extremidade do endoscópio e outro, o "mini-probe", apresenta o formato dos cateteres que habitualmente são utilizados nos procedimentos endoscópicos e, desse modo, é conduzido pelo canal do endoscópio de uso rotineiro, realizando-se, então, o estudo ecográfico. ${ }^{(15)}$

Para se obter interface adequada para a passagem do som pode-se realizar a infusão de líquido, ficando o ecoendoscópico imerso nesse líquido; geralmente é necessária a instilação de 250 a $300 \mathrm{ml}$ de água. No estudo do estômago, duodeno e reto pode ser empregada esta técnica ${ }^{16}$.

Em outras situações os ecoendoscópios apresentam, em suas extremidades, balões que podem ser insuflados com líquido (água), fornecendo interface adequada. 
Dentre as estruturas avaliadas por este método tem-se o esôfago e os cólons, assim como as estruturas próximas a eles ${ }^{16}$.

Os tumores subepiteliais também podem ser avaliados pela EE. A EE pode identificar o local de origem dessas lesões, como de submucosa (no caso dos lipomas) e de muscular própria (no caso de leiomioma e leiomiossarcoma) e permite, ainda, que compressões extrínsecas (como nos casos de linfonodos mediastinais) sejam prontamente identificadas, afastando-se a possibilidade de causas intramurais ${ }^{14}$.

A punção guiada pela EE controlada em tempo real pelo ultrassom, permite a colheita do material citológico por aspiração, para a qual utiliza agulha fina específica, na maioria das vezes com calibre $22 \mathrm{G}^{17-19}$. A ecoendoscopia associada à punção aspirativa com agulha fina (EE-PAAF) pode aumentar o grau de exatidão desse método e o estudo histológico permanece como o "padrão-ouro" para o diagnóstico definitivo dos $\operatorname{TSE}^{19}$.

A ecoendoscopia do trato gastrintestinal alto é realizada com sedação endovenosa e com paciente em decúbito lateral esquerdo. O exame tem duração média de 15 a 60 minutos. O examinador interpreta as imagens ultrassonográficas utilizando as endoscópicas como referência anatômica. ${ }^{(11)}$

O exame consiste na introdução do ecoendoscópio por via oral, aparelho que apresenta uma sonda de ultrassom na sua extremidade e é acoplado a uma central de ultrassonografia para o estudo metódico e sistemático de todo o trajeto percorrido até a segunda porção duodenal ${ }^{11}$.

\section{PAREDE DO TRATO GASTROINTESTINAL}

De modo geral a parede dos órgãos (esôfago, estômago e duodeno) contém cinco camadas ecográficas ${ }^{20}$. 
Vários trabalhos procuram estabelecer a correlação precisa entre essas camadas com as descritas em anatomia. Atualmente admite-se que exista a seguinte relação ${ }^{2-4}$ :

1. primeira camada (hiperecóica): onde se encontra o epitélio superficial mucoso com a interface do balão insuflado.

2. segunda camada (hipoecóica): é a mucosa profunda e a muscularis mucosae.

3. terceira camada (hiperecóica): é a submucosa com a camada superficial da muscularis propria.

4. quarta camada (hipoecóica): é a muscularis propria.

5. quinta camada (hiperecóica): é a serosa, adventícia ou a gordura adjacente (dependendo da estrutura de cada órgão)(Figura 1).

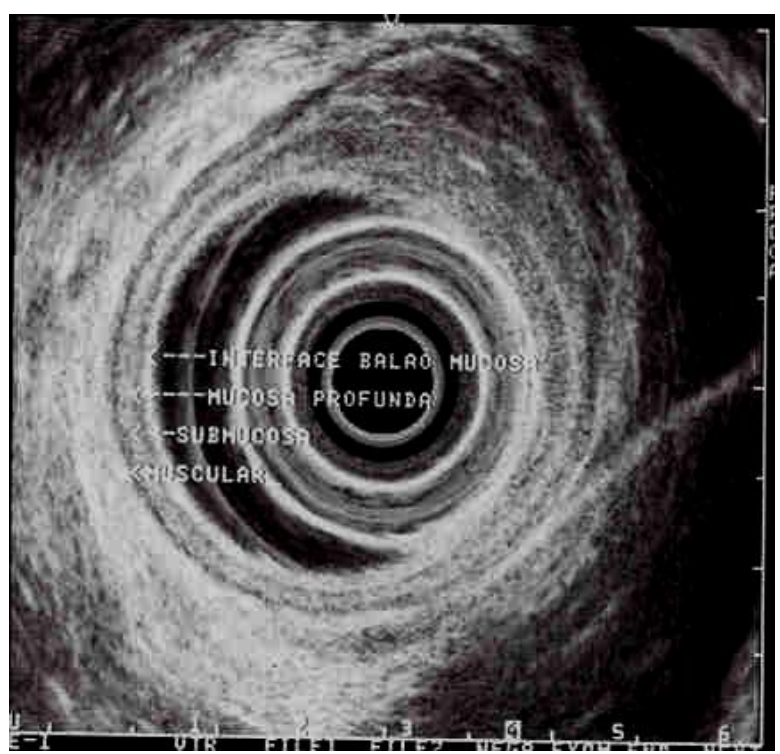

Figura 1: Aspecto ecográfico com sonda de $7,5 \mathrm{MHz}$ demonstrando as cinco camadas descritas

\section{O PAPEL DA ECOENDOSCOPIA NA AVALIAÇÃO DOS TSE}

O exame ecoendoscópico permite distinguir lesão intraparietal, que se origina da $1^{\mathrm{a}}$, $2^{\mathrm{a}}, 3^{\mathrm{a}}, 4^{\mathrm{a}}$ ou $5^{\mathrm{a}}$ camada da parede gastrintestinal, de CE, que comprime todas as cinco camadas. Portanto, mediante a EE é possível caracterizar a(s) camada(s) de origem da lesão e fazer, por conseguinte, a distinção entre lesão intramural de CE com grau de exatidão acima de $95 \%{ }^{22-29}$. 
As características ecográficas presentes nos TSE permitem a distinção teórica entre a natureza benigna ou maligna da lesão, subsidiando a indicação ou não de procedimentos como a punção ou a ressecção ${ }^{25}$.

A respeito da $\mathrm{CE}$, praticamente todos os órgãos ou estruturas vizinhas do trato gastrointestinal alto e baixo podem produzir imagens sugestivas de TSE. Ao produzir um abaulamento endoluminar suficiente a ponto de ser visualizado e interpretado como tal, o órgão ou a estrutura normal apresenta circunstâncias anatômicas locais de contato direto com o TGI produzindo assim uma imagem semelhante à do TSE e freqüentemente sem sintomas. Por outro lado, esse abaulamento pode ser secundário a processo expansivo extraluminar que comprime a parede do trato gastrointestinal, sendo visível por via endoscópica ${ }^{26}$.

A interpretação endoscópica e ecoendoscópica associa o raciocínio anatômico regional às características ecográficas normais dos órgãos adjacentes (Tabela 2).

Tabela 2: Correlação anatômica entre o sítio anatômico do TGI onde as CE são visualizadas e os possíveis órgãos responsáveis por elas.

\begin{tabular}{ll}
\hline Órgão & Órgãos responsáveis por compressões extrínsecas \\
\hline Esôfago & Átrio esquerdo, aorta torácica, linfonodos regionais aumentados \\
Estômago & $\begin{array}{l}\text { Lobo hepático esquerdo, vesícula biliar, baço, aorta abdominal, } \\
\text { Artéria esplênica, formações císticas pancreáticas, cólon, } \\
\text { tumor pancreático } \\
\text { Reto }\end{array}$ \\
\hline
\end{tabular}

Motoo e col. ${ }^{30}$, estudando 19 pacientes com CE, encontraram 16 delas causadas por órgãos ou estruturas normais e 3 por neoplasia. 
As estruturas vasculares são freqüentemente sugeridas pelo seu aspecto tubular, eventualmente pulsátil e confirmadas à EE pela aplicação do Doppler. Outro exemplo é o abaulamento endoluminar por órgão homogêneo, levemente hipoecóico, com bordas lisas e regulares na parede gástrica anterior, que sugere $\mathrm{CE}$ pelo lobo hepático esquerdo ou pela vesícula biliar $^{31}$. A CE que ocorre na porção proximal ou média do estômago pode derivar do baço. Além disso, a simples mudança de decúbito do paciente durante uma endoscopia digestiva pode desfazer a dúvida entre TSE e CE. O sinal ecoendoscópico que caracteriza a CE é a visualização da parede com todas as suas camadas normais elevadas e comprimidas pelo processo extramural ${ }^{32}$.

De acordo com a camada de origem e a aparência da lesão pode-se pressupor o diagnóstico etiológico dos TSE (Quadro 2). Por exemplo, enquanto uma lesão hiperecóica, homogênea, arredondada, com contorno regular, situada na $3^{\mathrm{a}}$ camada sugere lipoma outra hipoecóica, heterogênea, com forma e contornos irregulares e com áreas anecóicas no interior e situada na $4^{\mathrm{a}}$ camada sugere a presença de tumor estromal gastrintestinal ${ }^{23}$. Já a visualização de estruturas tubulares, anecóicas e com sinal do Doppler presente indica a natureza vascular da lesão. Pode haver combinações destas características, como a presença de algumas estruturas vasculares e outras anecóicas, císticas, de permeio a uma grande lesão hipoecóica, heterogênea situada na $4^{\mathrm{a}}$ camada que sugerem hipervascularização e sua natureza maligna ${ }^{27}$. 
Quadro 2: Relação entre a(s) camada(s) comprometida(s), a etiologia mais freqüente e a aparência dos TSE à EE $23,27,33,34$

\begin{tabular}{|l|l|l|}
\hline \multicolumn{1}{|c|}{ Camada } & \multicolumn{1}{|c|}{ Aparência } & \multicolumn{1}{|c|}{ Etiologia } \\
\hline $\mathbf{2}^{\mathbf{a}}$ ou $\mathbf{3}^{\mathbf{a}}$ camadas & Massa levemente hipoecóica, homogênea & Tumor carcinóide \\
\hline $\mathbf{2}^{\mathbf{a}}, \mathbf{3}^{\mathbf{a}}$ ou $\mathbf{4}^{\text {a }}$ camadas & $\begin{array}{l}\text { Estrutura hipoecóica ou de ecogenicidade mista (estruturas } \\
\text { tubulares ou ductais podem estar presentes) }\end{array}$ & Pâncreas ectópico \\
\hline $\mathbf{3}^{\mathbf{a}}$ camada & $\begin{array}{l}\text { Lesão hiperecóica, depressível, às vezes com aspecto } \\
\text { polipóide }\end{array}$ & Lipoma \\
\hline $\mathbf{3}^{\mathbf{a}}$ camada & Estruturas serpiginosas, tubulares, anecóicas, Doppler . & Variz \\
\hline $\mathbf{3}^{\mathbf{a}}$ camada & $\begin{array}{l}\text { Estruturas anecóicas, compressíveis, com borda bem } \\
\text { definida e Doppler (3 ou 5 cama ou 5 camadas sugerem } \\
\text { cisto de duplicação) }\end{array}$ & Cisto células \\
\hline $\mathbf{3}^{\mathbf{a}}$ camada & Massa hipoecóica, heterogênea com bordas regulares & $\begin{array}{l}\text { Tumor de } \\
\text { granulares }\end{array}$ \\
\hline $\mathbf{3}^{\mathbf{a}}$ camada & Lesão anecóica com contorno regular & Linfangioma \\
\hline $\mathbf{2}^{\mathbf{a}}, \mathbf{3}^{\mathbf{a}} \mathbf{e} \mathbf{4}^{\mathbf{a}}$ camada & $\begin{array}{l}\text { Massa hipoecóica com aspecto variável de acordo com o } \\
\text { comportamento benigno maligno da lesão (este com } \\
\text { contorno irregular, focos hiperecóicos e áreas anecóicas } \\
\text { anecóicas que sugerem malignidade) }\end{array}$ & Tumor estromal \\
\hline Qualquer uma ou todas & Massa hipoecóica e heterogênea com contorno irregular & Tumor metastático \\
\hline
\end{tabular}

\section{DIAGNÓSTICO DIFERENCIAL DOS TSE}

\section{TUMOR ESTROMAL GASTROINTESTINAL}

O TEGI representa um grupo de tumores mesenquimais que ocorrem no TGI, omento, mesentério ou retroperitônio, originários das células de Cajal, chamadas células "pacemaker", alteradas pela ativação contínua da proteína receptora tirosinaquinase transmembrana (KIT); expressam positivamente o antígeno CD117 e apresentam 1 de 3 aspectos histológicos: tipo fusiforme (70\%), tipo epitelióide $(20 \%)$ ou tipo misto $(10 \%)^{35}$.

O TEGI surge em geral em pacientes entre 55 e 65 anos de idade. Esta lesão representa cerca de $1 \%$ de todos os tumores gastrointestinais e $75 \%$ dos TSE sendo o estômago o órgão comprometido mais comum ${ }^{36,37}$.

Embora a maioria destas lesões seja benigna, permanecendo assintomática, 5-15\% delas são malignas ${ }^{38,39,40}$. Segundo Nickl e col. ${ }^{38} 16 \%$ dos TEGI têm potencial maligno indeterminado e segundo Pieri e col. ${ }^{41} 25 \%$ de todos os TEGI evoluem com recidiva local e 
$33 \%$ com recidiva à distância. Com relação à origem anatômica, o estômago é o sítio mais freqüente (50 a 60\%), seguido pelo intestino delgado (20 a 30\%), pelo intestino grosso (10\%), pelo esôfago $(5 \%)$ e por outros sítios na cavidade abdominal $(5 \% \text { dos casos })^{42}$.

\section{LEIOMIOMAS}

Os leiomiomas são tumores originários das células do músculo liso presente na parede do TGI. A sua incidência, após a reclassificação dos tumores mesenquimais, ainda não está definida na literatura, mas é considerada baixa ${ }^{42}$.

Da mesma maneira que os TEGI os leiomiomas são diagnosticados pela endoscopia digestiva alta (EDA) convencional de forma incidental e descritos como lesões únicas de aspecto subepitelial, podendo apresentar umbilicação central. A maioria tem curso clínico assintomático $^{42}$.

A distinção entre leiomiomas e TEGI é difícil e importante não apenas pela questão diagnóstica, mas também pelo prognóstico, pois os tumores de células musculares lisas, com baixa atividade mitótica, têm comportamento uniforme e evolução benigna ${ }^{43}$.

\section{LIPOMA}

O lipoma é um tumor benigno originário de células adiposas. Em frequiência, são os TSE encontrados em $2^{\circ}$ lugar durante a endoscopia e apresentam coloração amarelada e consistência facilmente compressível pelo aparelho. A análise histopatológica destes tumores revela uma coleção de tecido adiposo circundado por uma cápsula fibrosa ${ }^{44}$.

A EE é útil quando o aspecto endoscópico não é característico. Os lipomas são identificados à EE como lesões em geral solitárias, hiperecóicas, homogêneas, originadas na submucosa ( $3^{\mathrm{a}}$ camada), compressíveis pela pinça de biópsia. 
A avaliação ecoendoscópica destas lesões é especialmente importante se a ressecção endoscópica estiver sendo considerada como tratamento ${ }^{45,46,47}$.

\section{CISTOS}

As formações císticas do TGI constituem um grupo separado e raro de anomalias que têm origem principalmente no desenvolvimento embriológico, os cistos de duplicação, e que eventualmente podem ser produto de um processo inflamatório em resolução. No adulto, os cistos gastrintestinais são freqüentemente assintomáticos e descobertos de forma incidental durante exame radiológico ou endoscópico. Nas crianças podem ser descobertos pela presença de quadro clínico representado por dor, flatulência, sangramento e sintomas obstrutivos. Os cistos gástricos são raros, usualmente assintomáticos ${ }^{44}$.

A EE é fundamental para o esclarecimento da natureza da lesão e, por permitir o estudo minucioso da parede, evita o diagnóstico inadequado de lesões tumorais papiliformes com componente cístico predominante como lesões císticas. A EE-PAAF destas lesões, principalmente se houver espessamento segmentar de sua parede, permite eventualmente o diagnóstico citológico, o que é importante para orientar a decisão sobre o tratamento destas lesões, mediante punção, com observação ou drenagem endoscópica ou ressecção ${ }^{44}$.

\section{TUMOR DE ABRIKOSSOF}

Os tumores de Abrikossof são neoplasias freqüentemente benignas de provável origem neural que ocorrem no TGI. Apresentam incidência de aproximadamente 4 a $6 \%$ e cerca de um terço destas lesões estão situadas no esôfago; entre 1 e $3 \%$ dos casos são malignos. Podem incidir de forma sincrônica no mesmo órgão sendo a maioria dos pacientes assintomáticos. Em geral de achado incidental, estas lesões têm o diagnóstico definido pela biópsia realizada por endoscopia convencional ${ }^{48}$. 
A EE apresenta um papel complementar na avaliação destas lesões que se apresentam com aspecto hipoecóico sólido e se situam na $2^{\mathrm{a}}$ ou $3^{\mathrm{a}}$ camada. A EE contribui para a decisão terapêutica, demonstrando a camada comprometida e permitindo o planejamento da ressecção endoscópica se restrita à parede do TGI. Caso a lesão demonstre características de malignidade, a EE contribui no planejamento da estratégia cirúrgica; entretanto, o tratamento ideal ainda não está definido na literatura ${ }^{48}$.

\section{VARIZES E ESTRUTURAS VASCULARES}

As varizes são vasos dilatados, tortuosos, encontrados principalmente em pacientes com hipertensão portal. Elas aparecem no TGI em decorrência da conexão porto-sistêmica. As varizes esofagianas, as mais comuns, são freqüentemente diagnosticadas de forma correta pela endoscopia convencional. As varizes gástricas podem, ocasionalmente, apresentar aspecto polipóide atípico, sem coloração azulada, podendo ser confundidas com TSE. Macroscopicamente, a natureza vascular destas estruturas pode não ser tão evidente a ponto de evocá-la endoscopicamente, principalmente se o pregueado gástrico for proeminente. A importância da avaliação pela EE está no diagnóstico preciso desta situação evitando complicações secundárias, por vezes graves, como por exemplo, o sangramento posterior à biópsia do falso tumor ${ }^{21}$.

\section{MISCÊLANIA}

O tumor carcinóide, o tumor de células granulares, pâncreas ectópico, hematoma espontâneo de esôfago, entre outros, formam um grupo heterogêneo que tem em comum freqüência baixa. A aparência ecoendoscópica destas lesões tem sido descrita na literatura, mas o número limitado de casos não permite definir seu aspecto característico ${ }^{21}$. 
A descoberta endoscópica de um tumor subepitelial é frequente. Geralmente esse aspecto corresponde a uma compressão extrínseca ou a um tumor intramural. O diagnóstico definitivo dos TSE do TGI é difícil pelos métodos de imagem radiológicos convencionais; embora a maioria destas lesões seja benigna, seu diagnóstico pela endoscopia digestiva é limitado e as técnicas de biópsia convencionais não apresentam resultados satisfatórios. A EE tem apresentado importante papel na elucidação diagnóstica ${ }^{45}$. 
OJETIVOS 


\section{OBJETIVOS}

Comparação do desempenho da endoscopia digestiva alta com a da ecoendoscopia no diagnóstico diferencial entre tumor intramural e compressão extrínseca do esôfago, estômago e duodeno.

Avaliação do desempenho da ecoendoscopia no diagnóstico diferencial dos tumores intramurais. 
MÉTODOS 


\section{CASUÍSTICA E MÉTODO}

\subsection{MODELO, GRUPO, LOCAL E MÉTODO DE ESTUDO}

Trata-se de um estudo retrospectivo, utilizando o teste de instrumentos, comparativo entre a endoscopia digestiva alta e a ecoendoscopia na avaliação dos tumores subepiteliais do esôfago, estômago e duodeno.

Foi realizada análise de 188 exames endoscópicos feitos no período de janeiro de 2000 a dezembro de 2006, sendo que 22 pacientes foram excluídos por não ter sido submetidos à avaliação histológica. Desse modo, para o cumprimento do objetivo, o estudo foi feito em 176 prontuários no Setor de Endoscopia e Ecoendoscopia do Hospital 9 de Julho em São Paulo.

Inicialmente, todos os pacientes foram submetidos ao exame endoscópico por causas diversas; os que apresentaram abaulamento subepitelial do trato gastrointestinal, desde o esôfago até a segunda porção duodenal, foram remarcados para a realização de uma nova EDA seguida da EE.

Nesta segunda avaliação, alguns parâmetros foram sistematicamente avaliados e anotados, tanto no exame endoscópico quanto no ecoendoscópico, sempre pelo mesmo examinador.

O diagnóstico definitivo foi dado pelo exame histológico da lesão. A obtenção deste material foi conseguida com a utilização do ecoendoscópico mediante o uso da agulha para biópsia ou da PAAF, em lesões sólidas ou císticas, respectivamente. Na suspeita de lesão vascular, a EE foi complementada pelo Doppler colorido.

\subsection{CRITÉRIO DE INCLUSÃO}

Endoscopia digestiva e ecoendoscopia realizadas para avaliação de abaulamento subepitelial do esôfago, estômago e duodeno. 


\subsection{CRTÉRIO DE EXCLUSÃO}

Ausência de investigação histológica e/ou citológica documentada.

\subsection{VARIÁVEIS ESTUDADAS}

Antes dos exames, para todos os pacientes, os seguintes dados clínicos foram obtidos:

- Idade e sexo dos pacientes

- Sinais e sintomas sugestivos de doença do sistema digestório tais como achado incidental de abaulamento subepitelial em EDA prévia, disfagia, dor abdominal, sangramento digestivo e outros.

\subsection{ENDOSCOPIA DIGESTIVA ALTA}

Os exames endoscópicos foram realizados obedecendo-se ao seguinte protocolo:

- Os exames foram realizados após jejum de 12 horas

- Os pacientes foram monitorizados com oxímetro de pulso

- Medicação:

- Foram administradas $200 \mathrm{mg}$ de dimeticona, um polímero de silicone não absorvível, 5 minutos antes do exame, com a finalidade de diminuir a tensão superficial das bolhas gasosas.

- A anestesia tópica foi realizada com Lidocaína spray a $2 \%$ na parede posterior da faringe, com a finalidade de reduzir os reflexos faríngeos

- O sedativo utilizado foi o Midazolan, por via endovenosa, na dosagem de 0,035 a $0,05 \mathrm{mg} / \mathrm{kg}$ de peso 
- Posição do paciente: todos os pacientes foram examinados em decúbito lateral esquerdo

- O endoscópico foi conduzido desde a arcada dentária até a segunda porção duodenal para avaliação

Os seguintes parâmetros foram avaliados:

- Diagnóstico presuntivo do tipo de lesão

- Características da lesão: sede (esôfago, estômago ou duodeno), localização no órgão (proximal, medial ou distal) e tamanho $(\mathrm{cm})$.

O tamanho da lesão subepitelial foi estimado usando o diâmetro da pinça de biópsia aberta como referência.

\subsection{EXAME ECOENDOSCÓPICO}

O exame foi realizado seguindo os mesmos protocolos anteriormente descritos para o exame de endoscopia digestiva alta, acrescentado-se a utilização de um transdutor, (miniprobe), conduzido pelo canal do endoscópio de uso rotineiro.

Para se obter interface adequada para a passagem do som no estudo do estômago e duodeno utilizou-se a infusão 250 a $300 \mathrm{ml}$ de líquido diretamente na luz do órgão, ficando o ecoendoscópico imerso.

Na avaliação do esôfago, balões acoplados na extremidade do ecoendoscópio foram insuflados com líquido (água), fornecendo interface adequada.

Os seguintes parâmetros da lesão foram avaliados:

- Diagnóstico presuntivo da lesão

- Tamanho: em centímetros 
- Origem (camada): $1^{\mathrm{a}}, 2^{\mathrm{a}}, 3^{\mathrm{a}}, 4^{\mathrm{a}}, 5^{\mathrm{a}}$

- Ecogeneicidade: hipoecóica ou hiperecóica

- Lobularidade: sim ou não

- Áreas de necrose: presentes ou ausentes

- Sinal Doppler: presente ou ausente

- Aspecto da lesão: homogênea ou heterogênea

\subsection{EXAME HISTOLÓGICO}

- Resultado histológico da PAAF

- Resultado citológico

- Resultado da peça cirurgica

O material obtido foi fixado em formol a $10 \%$ tamponado e, em seguida, submetido a banhos sucessivos de alcoóis, com porcentagens cada vez menores de água até atingir o álcool absoluto para desidratação do material. Posteriormente, o material foi submetido à diafanização com xilol e à impregnação por parafina. Esta última foi realizada em dois banhos de parafina à temperatura de 57 a 60 graus Celsius seguida de inclusão em bloco de parafina. O bloco foi resfriado e, a seguir, foram realizados cortes histológicos seriados com espessura variando entre três e cinco micra.

As fitas de parafina com espécime foram colocadas em lâminas e levadas à estufa para selagem, seguindo, logo após, a coloração pelo método de hematoxilina-eosina. 


\subsection{ASPÉCTOS ÉTICOS}

De acordo com as exigências definidas pela resolução 196/96 do Conselho Nacional de Saúde e da Comissão Nacional de Ética em Pesquisa (CONEP), o projeto foi apreciado e aprovado pelo Comitê de Ética em Pesquisa do HCRP e da FMRP-USP (processo HCRP número 9012/2007). (anexo)

\subsection{ANÁLISE ESTATÍSTICA}

Todas as análises estatísticas foram realizadas usando o programa InsStat da GraphPad, versão para Windows.

Comparações dos resultados da EDA com os da EE foram feitos utilizando o teste exato de Fischer, considerando para o teste de hipótese Ho que os testes são independentes (não há associação). Se o valor de p for maior que 0,05 , não se rejeita Ho; se for menor, rejeita-se Ho.

A estimativa da qualidade da endoscopia e ecoendoscopia em relação à histologia foi realizada por meio da sensibilidade, especificidade, valor preditivo positivo, valor preditivo negativo e acurácia.

Análise de concordância entre endoscopia e ecoendoscopia foi feita mediante a utilização do coeficiente de Kappa. 


\section{RESULTADOS}

\subsection{GRUPO DE ESTUDO}

A idade variou de 10 a 87 anos, com média de 62,5 anos e predomínio na quinta e sexta décadas. Oitenta e três (47\%) eram homens e 93 (53\%) mulheres.

\subsection{DADOS EPIDEMIOLÓGICOS}

A indicação da EDA inicial foi feita por manifestações clínicas diversas, porém, o achado incidental de abaulamento durante o exame foi a principal causa relatada para a investigação (Figura 2).

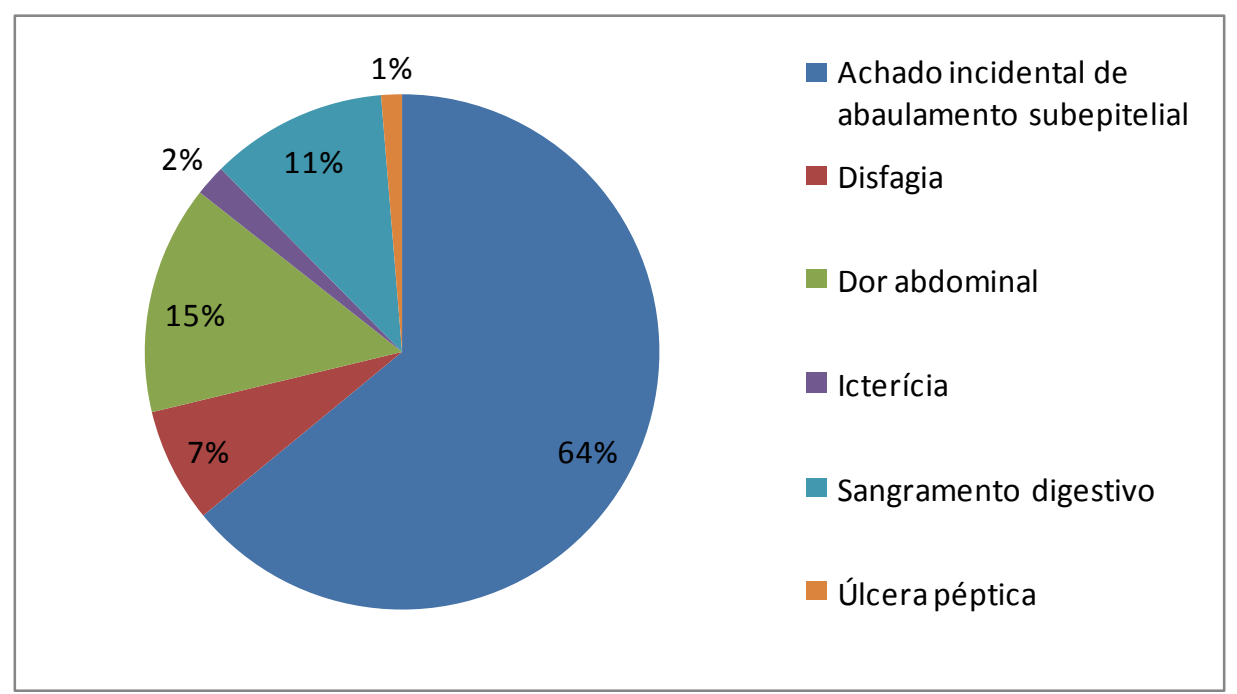

Figura 2: Distribuição das indicações da EDA inicial

\subsubsection{TUMORES SUBEPITELIAIS}

Do total de 176 exames avaliados com tumores subepiteliais, cento e cinqüenta e três (87\%) apresentavam lesão intramural e vinte e três (13\%) compressão extrínseca (Figura 3). 


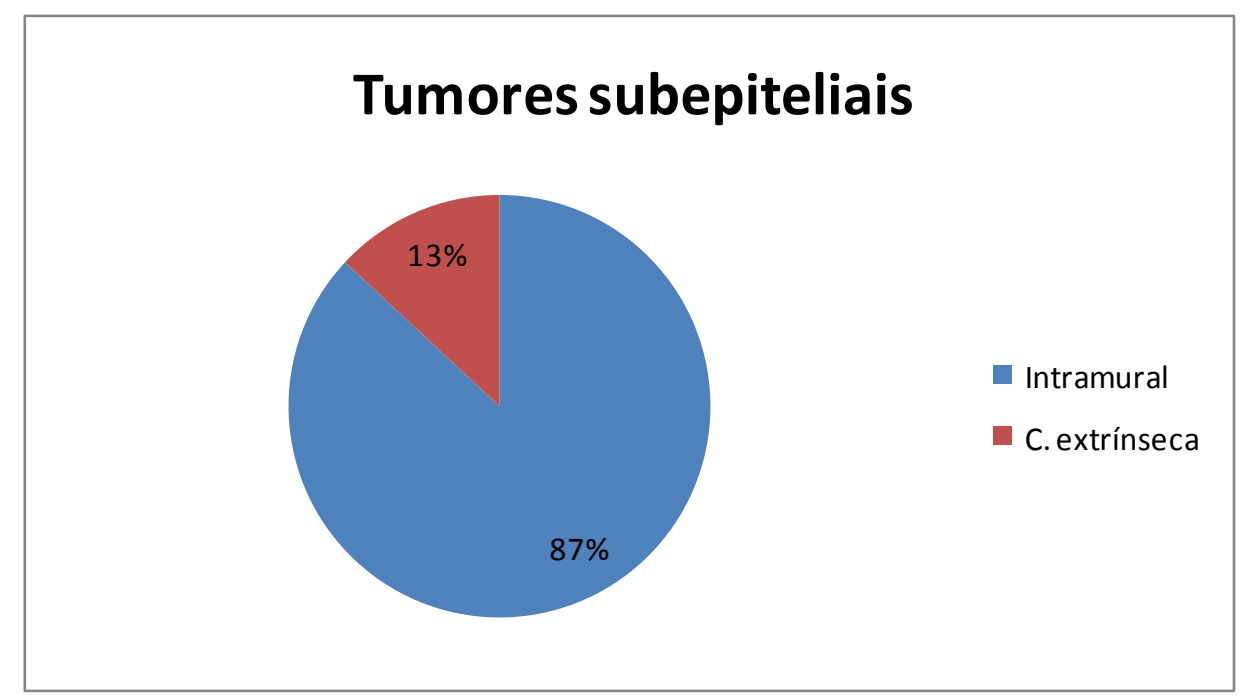

Figura 3: Distribuição quanto aos tipos de lesões subepiteliais

\subsubsection{COMPRESSÃO EXTRÍNSECA}

No grupo de pacientes com compressão extrínseca, as imagens sugestivas de TSE

(Figura 4) foram produzidas pelas seguintes estruturas: em sete (31\%) o fígado, em cinco (22\%) o baço, em quatro (18\%) a vesícula, em cinco (22\%) cisto de pâncreas, em um (4\%) cisto broncogênico e em um (4\%) indeterminada (Figura 5).

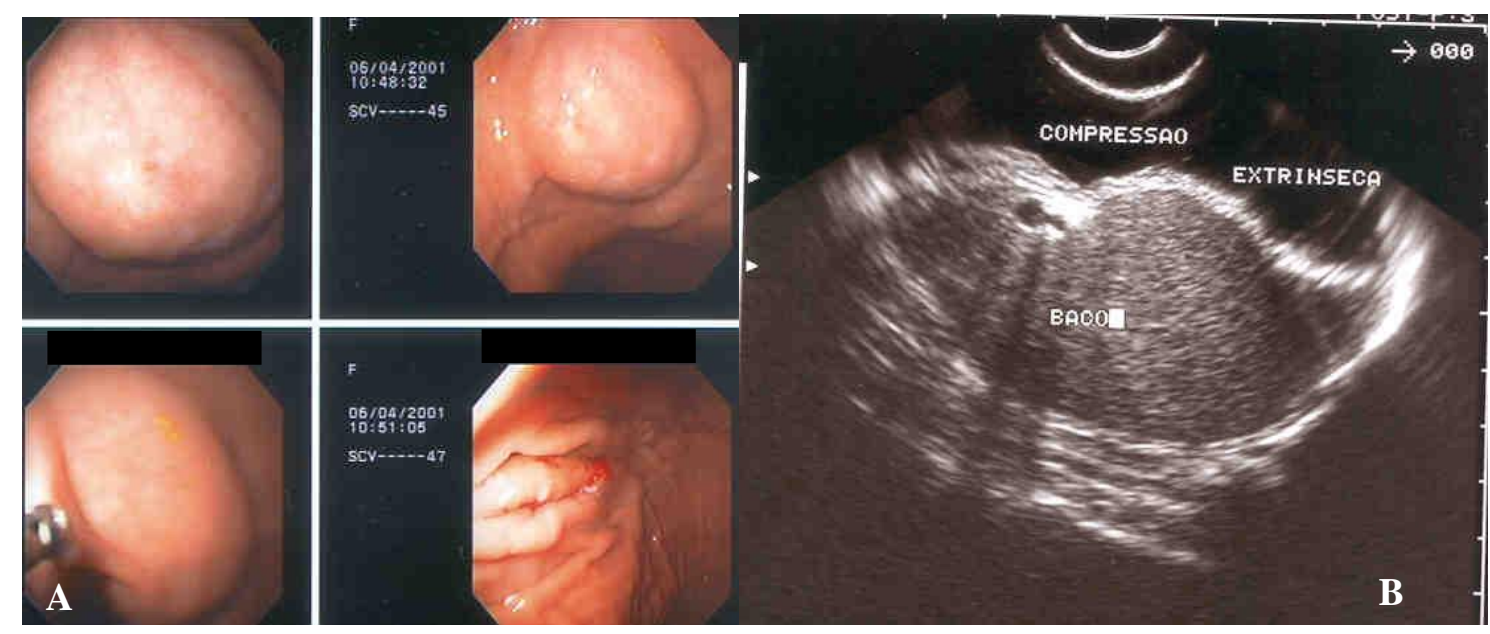

Figura 4: A Imagem endoscópica de abaulamento da parede do terço proximal gástrico. Nota-se o sinal da tenda que em seguida desaparece com a mudança de decúbito da paciente. B Imagem ecoendoscópica que mostra o baço comprimindo a parede gástrica. 


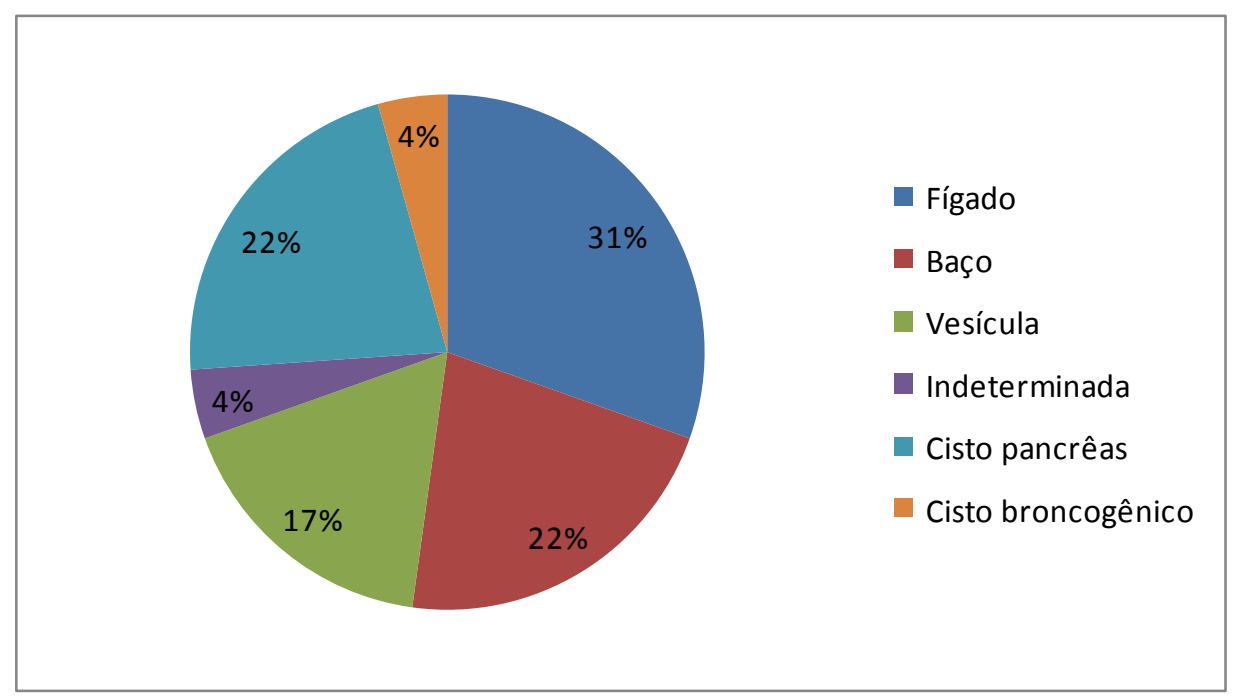

Figura 5: Distribuição quanto às causas de compressão extrínseca

\subsubsection{TUMORES INTRAMURAIS}

No grupo de pacientes com tumores intramurais as imagens sugestivas de TSE (Figura 6) foram produzidas pelas seguintes estruturas: em noventa e quatro (62\%) TEGI, em vinte e dois (15\%) leiomioma, em quinze (10\%) Abrikossof, em oito (5\%) lipoma, em três (2\%) cisto duodenal, em três (2\%) cisto gástrico, em dois (1\%) papila duodenal, em dois (1\%) indeterminada, em dois (1\%) pólipo duodenal e em dois (1\%) variz. (Figura 7).
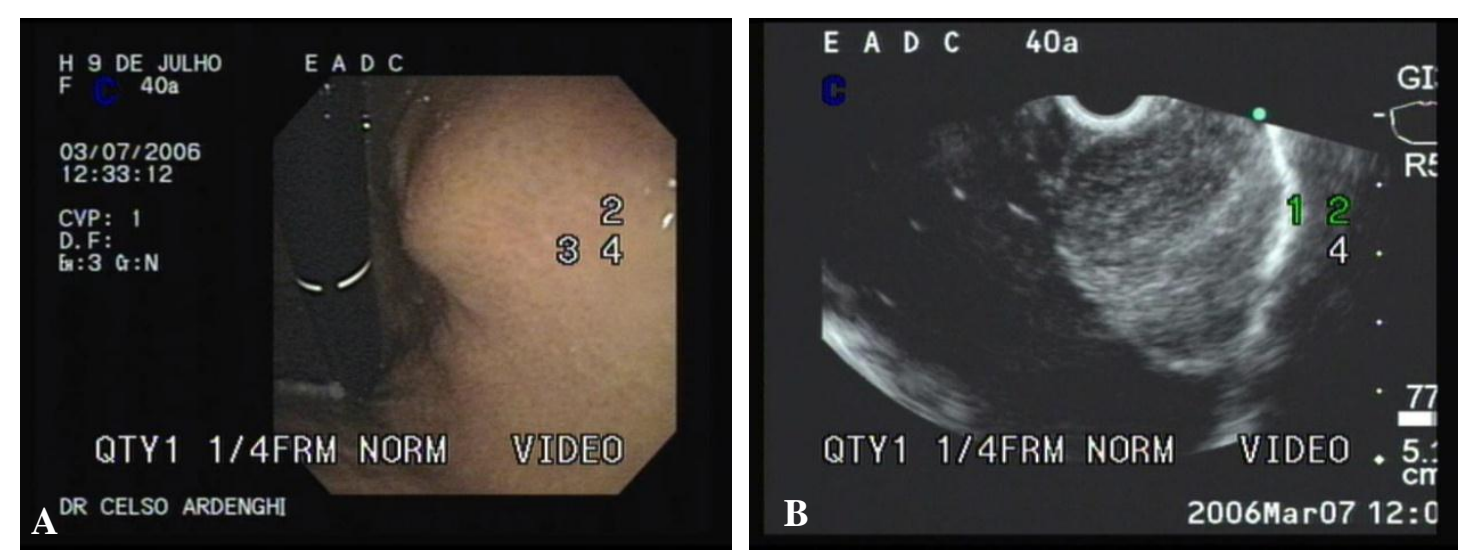

Figura 6: (A) Imagem endoscópica de leiomioma de TSE. (B) Imagem ecoendoscópica. 


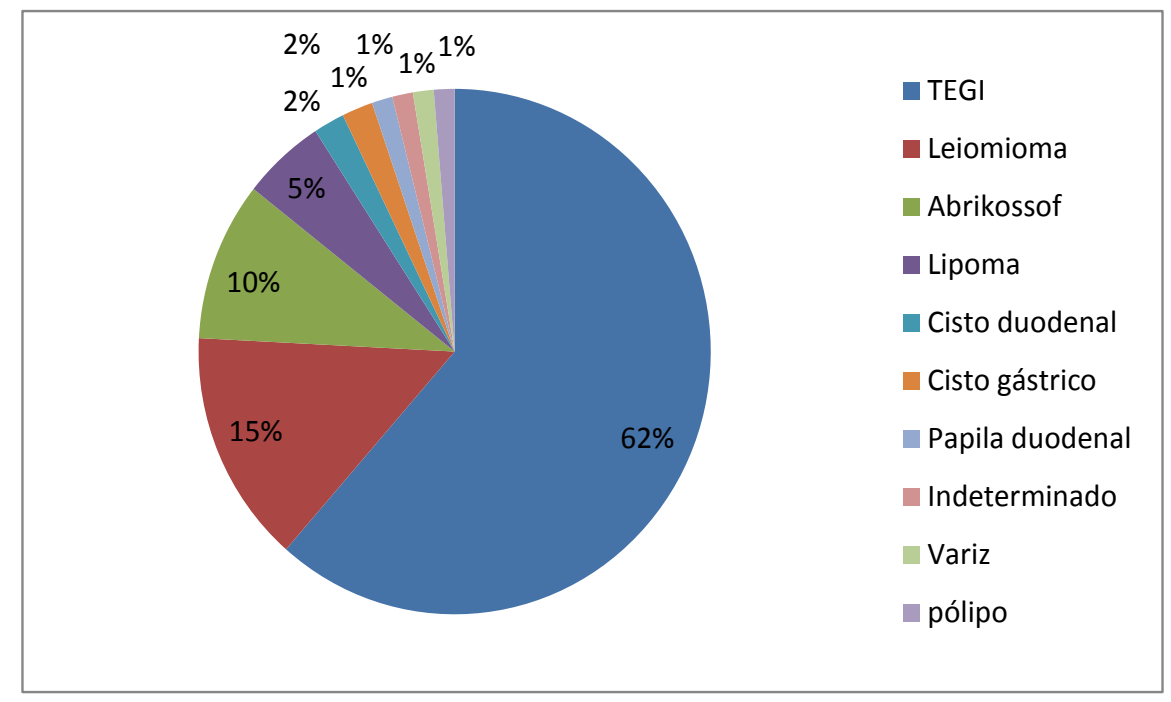

Figura 7: Distribuição quanto aos tipos de lesões intramurais

\subsubsection{CAMADA DE ORIGEM}

As camadas do TGI acometidas nos tumores intramurais estão representadas na Figura 8:

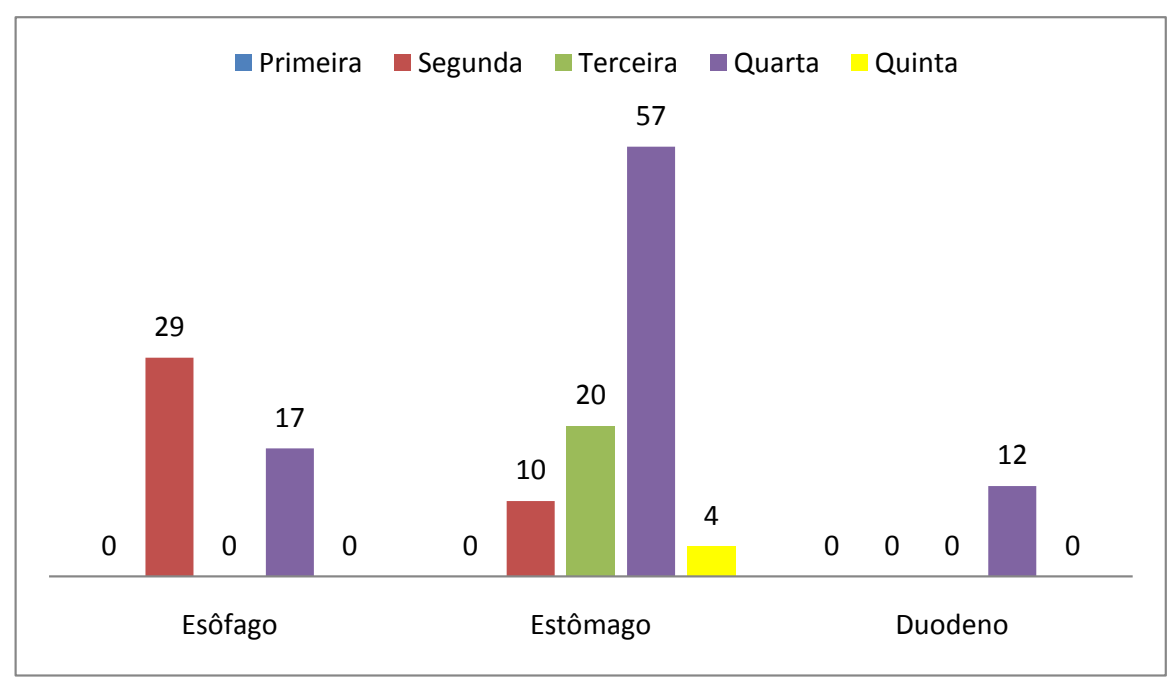

Figura 8: Distribuição dos tumores intramurais de acordo com a camada de origem 


\subsubsection{LOCALIZAÇÃO NO ÓRGÃO}

Quanto à localização, proximal, medial ou distal dos tumores intramurais nos órgãos, sendo que para o duodeno a primeira porção refere-se à localização medial e segunda porção à distal, obteve-se os seguintes resultados (Figura 9):

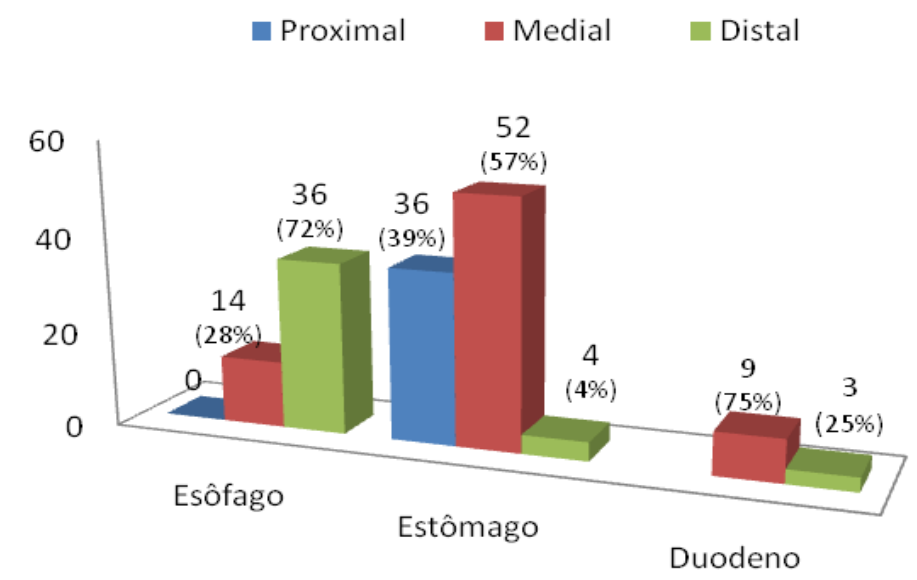

Figura 9: Distribuição dos tumores intramurais nas diferentes porções dos órgãos

\subsection{AVALIAÇÃO ENDOSCÓPICA E ECOENDOSCÓPICA DOS TUMORES INTRAMURAIS}

\section{TUMOR ESTROMAL GASTROINTESTINAL}

O aspecto ecoendoscópico do TEGI foi variável, de forma genérica, caracterizado como uma lesão hipoecóica, ovóide ou elíptica, pediculada ou multilobulada e situada na $2^{\text {a }}$ ou $4^{\mathrm{a}}$ camada (Figura 10 e 11). O aspecto endoscópico foi semelhante ao diagnóstico histológico em menos da metade dos casos.
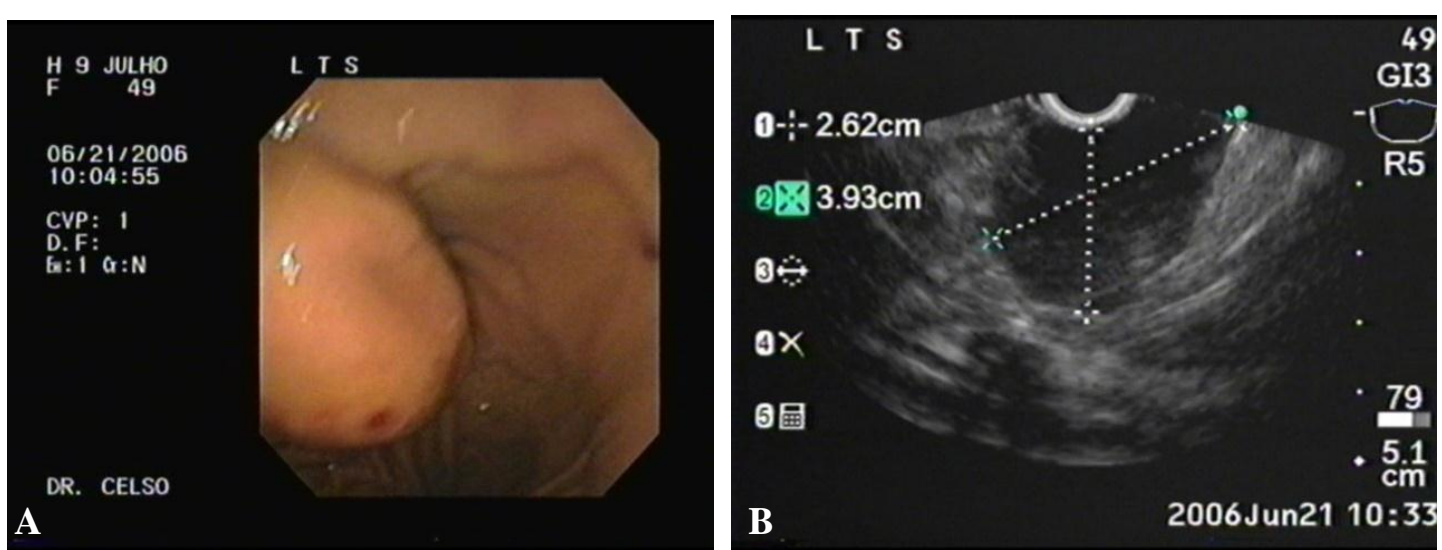

Figura 10: A. Imagem endoscópica B. Imagem ecoendoscópica de um TEGI. Nota-se imagem hipoecóica, heterogênea e de limites precisos. 


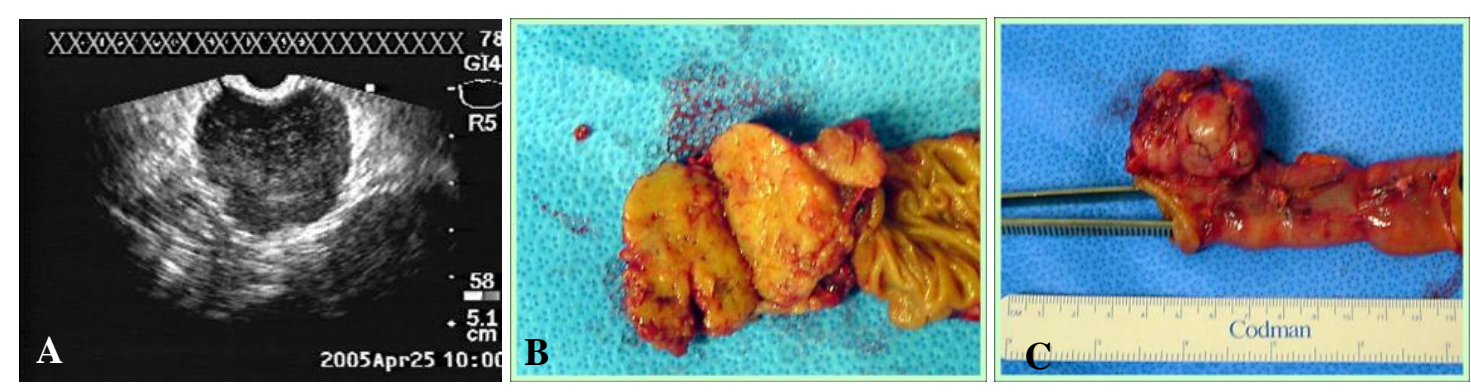

Figura 11: A. Imagem ecoendoscópica de tumor nodular hipoecóico, homogêneo de limites imprecisos, que mimetizava tumor neuroendócrino do pâncreas com abaulamento na segunda porção duodenal. B e C diagnóstico citológico do material colhido pela PAAF foi confirmado pela histologia da peça cirúrgica (TEGI).

\section{LEIOMIOMAS}

À EE estas lesões apresentaram aspecto ecográfico semelhante ao dos TEGI, descritos como lesões hipoecóicas, homogêneas, de tamanho variável (a maioria $<2 \mathrm{~cm}$ ), forma ovóide ou redonda com contorno regular e bem definido, situadas contíguas à $2^{\mathrm{a}}$ (Figura 12) ou $4^{\mathrm{a}}$ camada (Figura 13) da parede do TGI, onde existia tecido muscular. O aspecto endoscópico foi igual ao resultado histológico em 8 dos 22 casos.
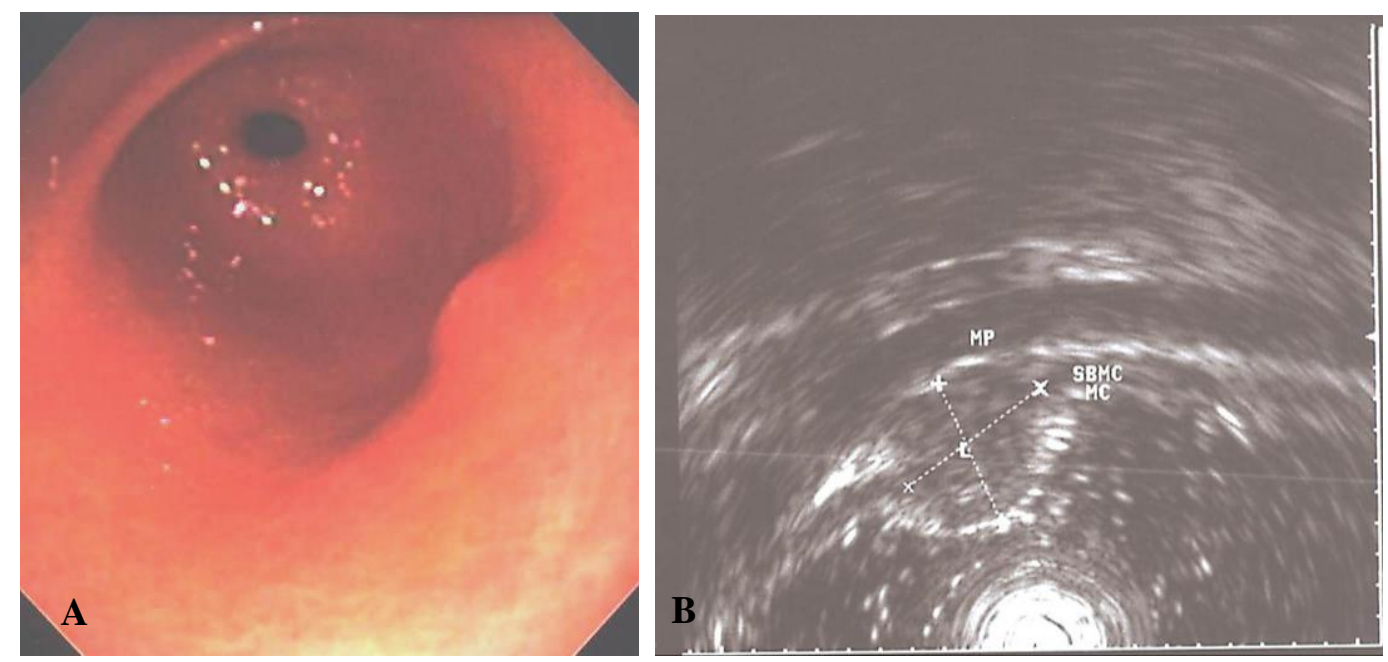

Figura 12: A. Imagem endoscópica de um leiomioma, localizado no antro gástrico. B. nota-se área arredondada de limites precisos, hipoecóica, originária da $2^{\mathrm{a}}$ camada. Observa-se a muscular própria (mp) intacta. 

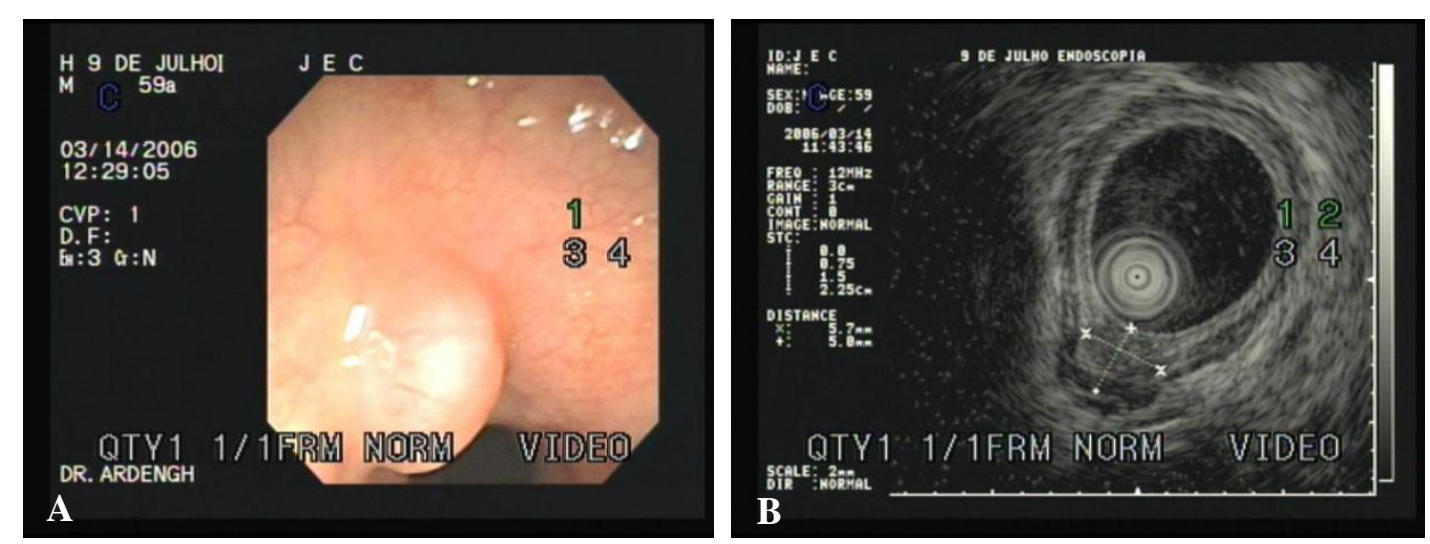

Figura 13: A. Imagem endoscópica de um leiomioma esofagiano. B. nota-se lesão hipoecóica, arredondada e de limites precisos.

\section{LIPOMA}

A EE foi útil quando o aspecto endoscópico não foi característico. Os lipomas foram identificados à EE como lesões em geral solitárias, hiperecóicas, homogêneas, originadas na submucosa ( $3^{\text {a }}$ camada) e compressíveis pela pinça de biópsia (Figuras 14 e 15). O aspecto endoscópico foi sugestivo em sete dos oito casos.
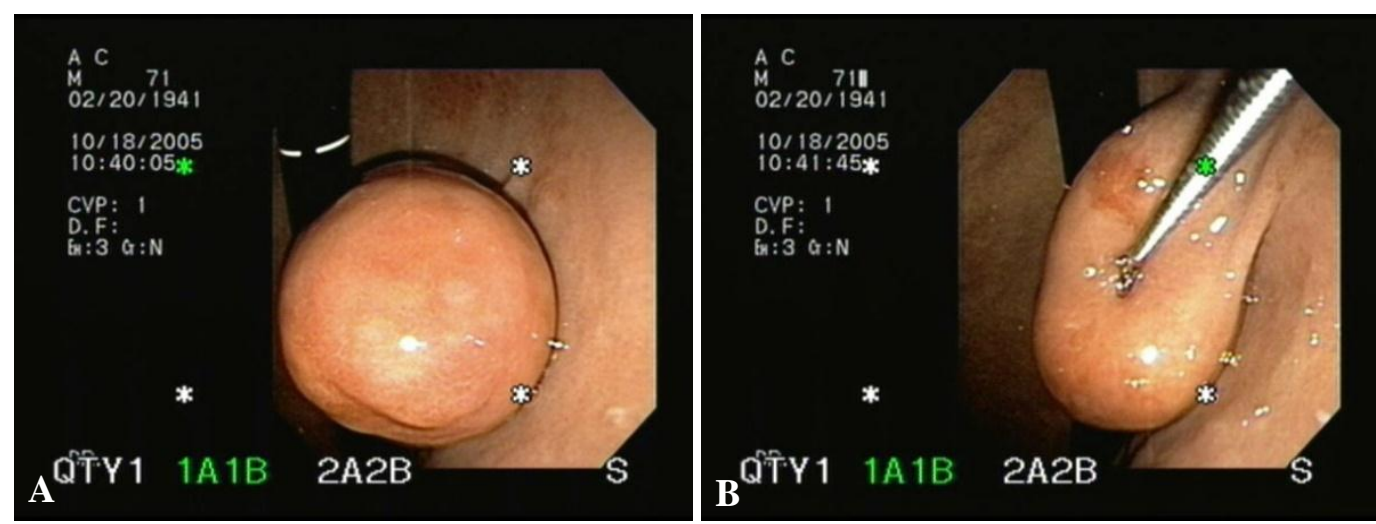

Figura 14: Imagens endoscópicas de lipoma, compressível pela pinça de biópsia. 


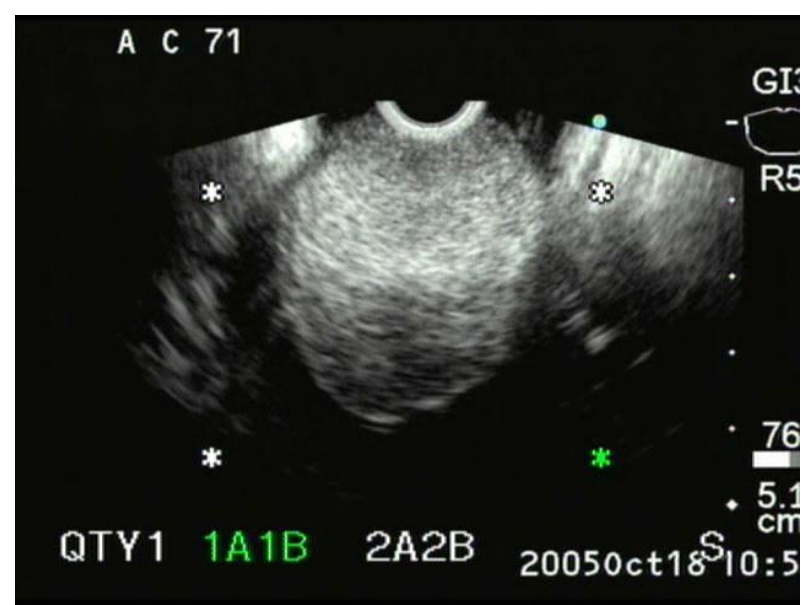

Figura 15: Imagem ecoendoscópica do mesmo linfoma da figura 14. Observa-se lesão subepitelial hiperecóica originária da terceira camada.

\section{VARIZES E ESTRUTURAS VASCULARES}

À EE as varizes foram demonstradas como estruturas tubulares anecóicas de aspecto serpiginoso, com contorno bem definido (Figura 16), facilmente compressíveis pelo aparelho e situadas na $3^{\mathrm{a}}$ camada. O sinal do Doppler positivo ressalta o fluxo sanguíneo presente e reforça o diagnóstico de estrutura vascular (Figura 17).
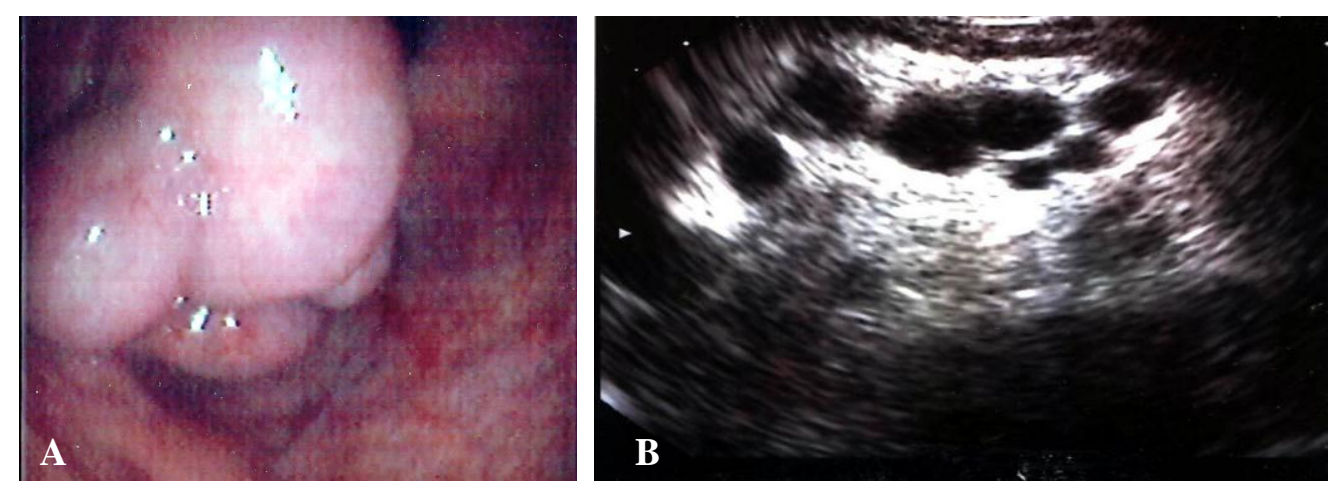

Figura 16: A. Imagens endoscópica B. Imagem ecoendoscópica de varizes de fundo gástrico 

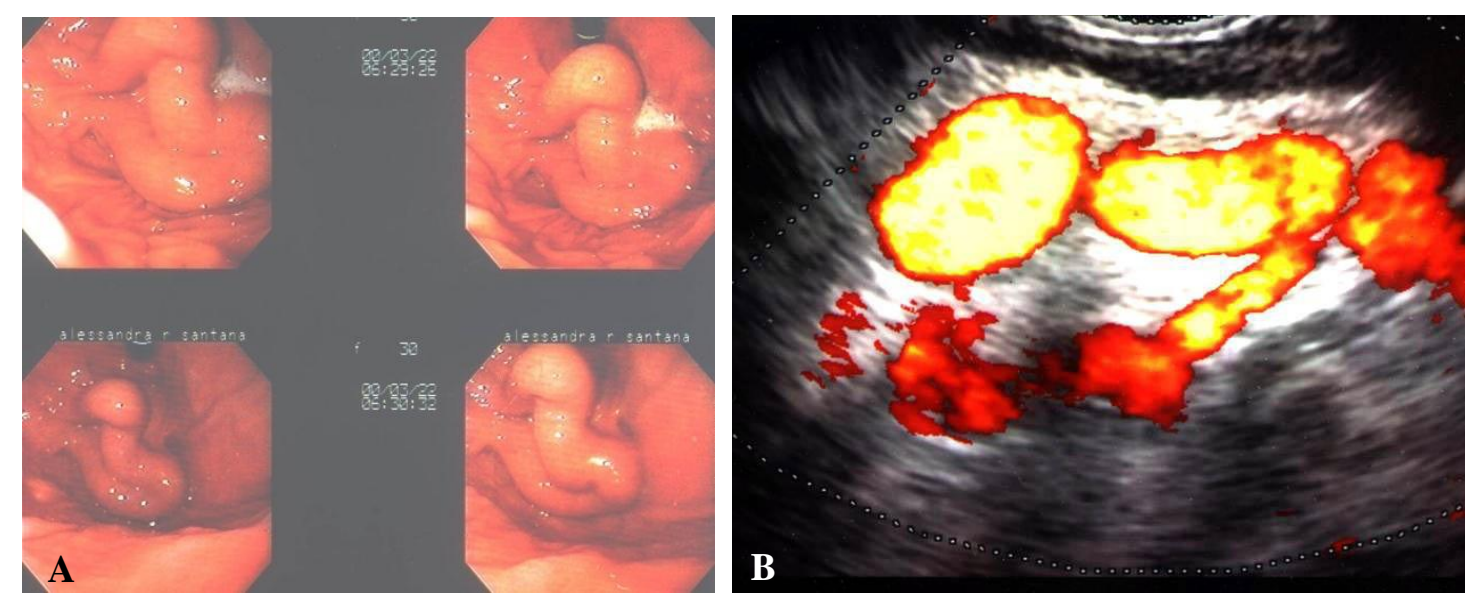

Figura 17: A. Imagem endoscópica de varizes de fundo gástrico. B. Imagem ecoendoscópica com estruturas vasculares pérvias e sinal de Doppler positivo

\section{CISTOS}

Os cistos foram visualizados como lesões anecóicas, arredondadas ou ovóides, com contorno bem definido e sem sinal de Doppler, situadas na $3^{\text {a }}$ camada da parede do TGI. Não foram tão facilmente compressíveis como as varizes (Figura 18).
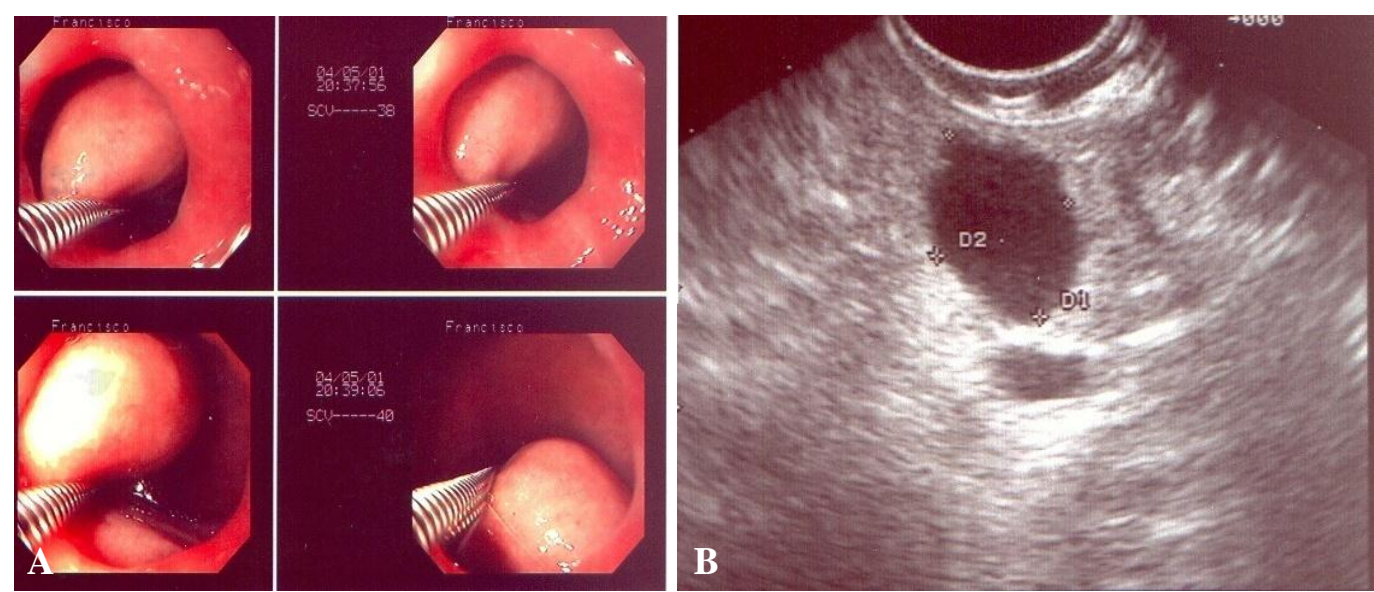

Figura 18: A. Imagem endoscópica B. Imagem ecoendoscópica de cisto gástrico 


\section{TUMOR DE ABRIKOSSOF}

A EE apresentou papel complementar na avaliação destas lesões, que se apresentaram com aspecto hipoecóico sólido e estavam situados na $2^{\mathrm{a}}$ ou $3^{\mathrm{a}}$ camada (Figura 19). A EE contribuiu para a decisão terapêutica demonstrando a camada comprometida e permitindo o planejamento de ressecção endoscópica, se restrita à parede do TGI.
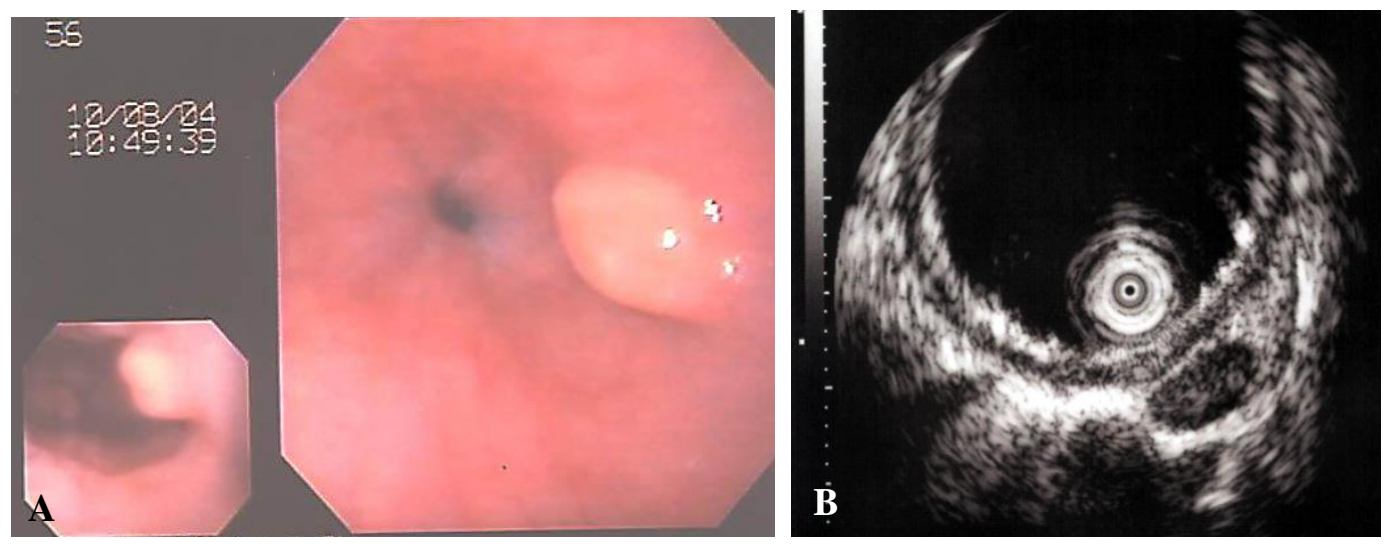

Figura 19: A. Imagem endoscópica de tumor de Abrikossof B. Nódulo hipoecóico arredondado e de pequenas proporções.

\subsection{ANÁLISE ESTATÍSTICA DO TESTE DE INSTRUMENTOS COMPARATIVO ENTRE EDA E EE NA AVALIAÇÃO DOS TSE}

\subsubsection{AVALIAÇÃO DAS COMPRESSÕES EXTRÍSECAS}

Os resultados encontrados na EDA foram: falso-positivo(FP) 1, falso-negativo(FN) 13, verdadeiro-positivo(VP) 9 e verdadeiro-negativo(VN) 0. Desse modo foram obtidos os valores de: sensibilidade 0,41 , especificidade 0,0 , valor preditivo positivo(VPP) 0,9 , valor preditivo negativo(VPN) 0,0 e acurácia 0,39 (Tabela 3).

$\mathrm{Na}$ análise estatística para diagnóstico de compressões extrínsecas, o valor encontrado de p $(0,43)$ foi maior que 0,05 , então não se rejeita Ho, ou seja, não há associação entre o exame endoscópico e o histológico para o diagnóstico de CE.(Tabela 3). 
$\mathrm{Na}$ EE os resultados foram: FP (0), FN (1), VP (21) e VN (1). Obteve-se, com isso, os seguintes valores: sensibilidade $(0,95)$, especificidade $(1,0)$, VPP $(1,0)$, VPN $(0,5)$ e acurácia $(0,95)$ (Tabela 4).

$\mathrm{Na}$ análise estatística para diagnóstico de compressões extrínsecas, o valor encontrado de $\mathrm{p}(0,08)$ foi maior que 0,05 , então não se rejeita Ho, ou seja, não há associação entre o exame ecoendoscópico e o histológico para o diagnóstico de CE. (Tabela 4).

Tabela 3 - EDA x Histologia no Diagnóstico de Compressão Extrínseca

\begin{tabular}{llccr}
\hline & & \multicolumn{2}{c}{ Histologia } & \\
\cline { 3 - 5 } & & & & \\
& & Positivo & & Total \\
\hline \multirow{2}{*}{ EDA } & Positivo & 9 & 1 & 10 \\
& Negativo & 13 & 0 & 13 \\
\hline Total & & 20 & 1 & 23 \\
\hline
\end{tabular}

Tabela 4 - EE x Histologia no Diagnóstico de Compressão Extrínseca

\begin{tabular}{cccrr}
\hline & & \multicolumn{2}{c}{ Histologia } & \\
\cline { 3 - 5 } & & & & \\
& & Positivo & & Total \\
\hline \multirow{2}{*}{$\mathrm{EE}$} & Positivo & 21 & 0 & 21 \\
& Negativo & 1 & 1 & 2 \\
\hline Total & & 22 & 1 & 23 \\
\hline
\end{tabular}

\subsubsection{AVALIAÇÃO DOS TUMORES INTRAMURAIS}

$\mathrm{Na}$ avaliação dos tumores intramurais, os resultados encontrados na EDA foram: FP (1), FN (20), VP (131) e VN (1). Desse modo foram obtidos os valores de: sensibilidade $(0,87)$, especificidade $(0,5)$, VPP $(0,99)$, VPN $(0,05)$ e acurácia $(0,86)$ (Tabela 5).

$\mathrm{Na}$ análise estatística para diagnóstico de tumor intramural, o valor encontrado de $\mathrm{p}$ $(0,25)$ foi maior que 0,05 , então não se rejeita Ho, ou seja, não há associação entre o exame endoscópico e o histológico para o diagnóstico de TI. (Tabela 5). 
Na EE os resultados foram: FP (0), FN (1), VP (150) e VN (2). Obteve-se, com isso, os seguintes valores: sensibilidade $(0,99)$, especificidade $(1,0)$, VPP $(1,0)$, VPN $(0,66)$ e acurácia $(0,99)$ (Tabela 6).

$\mathrm{Na}$ análise estatística para diagnóstico de tumor intramural, o valor encontrado de $\mathrm{p}$ (0,0003) foi menor que 0,05 , então rejeita-se Ho, ou seja, há associação entre o exame ecoendoscópico e o histológico para o diagnóstico de TI.(Tabela 6)

Tabela 5 - EDA x Histologia no Diagnóstico de Tumor Intramural

\begin{tabular}{llcrrr}
\hline & & \multicolumn{2}{c}{ Histologia } & \\
\cline { 3 - 5 } & & & & \multicolumn{2}{c}{ Total } \\
\hline \multirow{2}{*}{ EDA } & Positivo & 131 & 1 & 132 \\
& Negativo & 20 & 1 & 21 \\
\hline Total & & 151 & 2 & 153 \\
\hline
\end{tabular}

Tabela 6 - EE x Histologia no Diagnóstico de Tumor Intramural

\begin{tabular}{cccrr}
\hline & & \multicolumn{2}{c}{ Histologia } & \\
\cline { 3 - 5 } & & & & \multicolumn{2}{c}{ Total } \\
\hline \multirow{2}{*}{ EE } & Positivo & 150 & 0 & 150 \\
& Negativo & 1 & 2 & 3 \\
\hline Total & & 151 & 2 & 153 \\
\hline
\end{tabular}




\subsubsection{AVALIAÇÃO PELO MÉTODO KAPPA}

A concordância dos achados do exame endoscópico com o exame ecoendoscópico foi verificada pelo método Kappa. Segundo Landis e Koch o coeficiente Kappa pode ter a seguinte interpretação:

$\kappa<0,00$ concordância inadequada;

$0,00<\kappa<0,20$ concordância muito leve;

$0,21<\kappa<0,40$ concordância leve;

$0,41<\kappa<0,60$ concordância moderada;

$0,61<\kappa<0,80$ concordância substancial;

$0,81<\kappa<1,00$ concordância quase perfeita.

Os resultados do exame endoscópico e os do exame ecoendoscópico apresentaram, pelo coeficiente de Kappa, concordância inadequada $(\kappa=-0,01)$ no diagnóstico das compressões extrínsecas e concordância muito leve $(\kappa=0,13)$ no diagnóstico dos tumores intramurais 
DisCUSSÃo 


\section{DISCUSSÃO}

Diversos estudos têm mostrado a utilidade da ecoendoscopia na avaliação e conduta das lesões subepiteliais ${ }^{4,47}$. No entanto, um estudo comparativo do desempenho da endoscopia digestiva alta com o da ecoendoscopia no diagnóstico diferencial dos tumores subepiteliais apenas do esôfago, estômago e duodeno não foi encontrado na literatura, com exceção de estudos que compararam a EDA e EE na diferenciação entre tumor intramural e lesão extramural de todo trato digestivo ${ }^{46,47}$, sem particularização adequada do órgão sede.

A descoberta endoscópica de um tumor subepitelial é freqüente; geralmente o aspecto endoscópico corresponde ao de compressão extrínseca ou de tumor intramural.

O endoscopista deve analisar atentamente a lesão quanto ao tamanho, formato, mobilidade, consistência ao toque da pinça, pulsação, cor, aspecto da superfície mucosa. Um recurso adicional para distinguir a massa intramural da compressão extrínseca é observar o efeito da mudança de decúbito e da insuflação de ar no abaulamento. O desaparecimento completo do abaulamento com essas manobras sugere compressão extrínseca. A definição etiológica dos tumores subepiteliais baseada apenas no exame endoscópico oferece dificuldades até para o examinador experiente. O diagnóstico por vezes torna-se difícil, mesmo após a obtenção de biópsias pela EDA e, antes de executá-la, o endoscopista deve observar cuidadosamente a lesão subepitelial. Se houver suspeita de natureza vascular, a biópsia deve ser evitada.

A primeira decisão a ser tomada diante de lesão subepitelial é se deve ignorá-la ou prosseguir com a investigação.

A conduta deve ser individualizada, baseando-se em parâmetros como tamanho e aspecto da lesão, presença de sintomas, condições clínicas do paciente e recursos propedêuticos disponíveis. 
Segundo a literatura ${ }^{26}$, nódulos subepiteliais inferiores a $1 \mathrm{~cm}$, assintomáticos, em pacientes idosos ou com co-morbidades podem ser acompanhados sem necessidade de condutas cirúrgicas, ressalvadas eventuais complicações.

Quando indicada, a ecoendoscopia tem como objetivo definir se o abaulamento resulta de massa intramural ou de compressão extrínseca.

Neste trabalho, procurou-se comparar o desempenho da endoscopia digestiva alta e da ecoendoscopia na avaliação de tumores subepiteliais do esôfago, estômago e duodeno, quanto ao diagnóstico presuntivo e o desempenho da EE na identificação etiológica das lesões intramurais.

Segundo a literatura, os TSE ocorrem de forma uniforme entre homens e mulheres, havendo predomínio após a $5^{\mathrm{a}}$ década de vida, sendo os pacientes, em sua maioria, assintomáticos 5 .

Nesse estudo, os aspectos epidemiológicos são semelhantes aos citados na literatura, com idade variando de 10 a 87 anos, com média de 62,5 anos e com predomínio na quinta e sexta décadas. A prevalência de homens e mulheres foi semelhante, próximo de $50 \%$. A maioria dos pacientes era assintomática (64\%), nos quais a presença do TSE foi achado incidental.

Para elucidação da natureza do abaulamento da parede do tubo digestivo foram avaliados os resultados dos exames endoscópico e ecoendoscópico, complementados com o resultado histológico e/ou citológico. A maioria dos pacientes estudados apresentou tumor intramural (87\%) e os restantes compressão extrínseca (13\%) em semelhança com o estudo de Boyce e col. ${ }^{62}$, que demonstraram $78 \%$ de TI e 22 de CE mediante a EE. 
Motoo e col, estudando 19 pacientes com CE, encontraram 16 delas causadas por órgãos ou estruturas normais (7 pela artéria esplênica, 5 pelo baço, 2 pelo pâncreas normal, 1 pela vesícula e 1 pelo cólon) e 3 por neoplasia ( 2 por neoplasia hepática e 1 por neoplasia do omento) ${ }^{50}$.

Em estudo prospectivo Fletcher e col, encontraram 22 pacientes nos quais a CE foi causada apenas por estruturas normais (12 pelo fígado, 7 pelo baço e 3 por cisto pancreático $)^{42}$.

No presente estudo, no grupo de 23 pacientes com compressão extrínseca as imagens sugestivas de TSE foram produzidas principalmente pelo fígado (31\%), baço (22\%), cisto pancreático $(22 \%)$ e nenhum caso por neoplasia. O achado de um caso de CE por cisto broncogênico neste estudo parece inédito, pois não se encontrou outras descrições semelhantes nos trabalhos pesquisados ${ }^{42,50,51}$. Houve um caso que, mesmo após o paciente ter sido submetido à cirurgia exploradora, não se encontrou a causa do abaulamento subepitelial, ficando com diagnóstico indeterminado.

Entre os pacientes com tumor intramural, o TEGI foi encontrado em $62 \%$, seguido pelo leiomioma em $15 \%$. Em dois casos também não foi possível determinar a causa do abaulamento, mesmo após remoção da suposta lesão e análise histopatológica, sendo a causa catalogada como indeterminada. A presença de TEGI como a causa mais freqüente de TI também é relatada na literatura pertinente ${ }^{52,53,54}$, porém, este estudo mostrou o leiomioma como sendo a segunda lesão mais freqüente, diferentemente de alguns trabalhos publicados que mostraram ser o lipoma ${ }^{52,53,54}$. Desse modo, a maioria das lesões vistas por meio da endoscopia é oriunda da própria parede do órgão, em sua maioria constituída por TEGI, leiomiomas e lipomas.

Fusaroli e col. ${ }^{51}$ seguiram 40 pacientes com TSE por 13 anos demonstrando que as lesões estavam situadas predominantemente no estômago (31) e esôfago (9). 
Yasuda e col. ${ }^{47}$ estudaram prospectivamente 52 pacientes com TSE e observaram que as lesões se encontravam na seguinte ordem de prevalência: estômago (23), esôfago (22), duodeno (2) e cólon (4).

Hwang e col. ${ }^{61}$ estudaram 68 pacientes, nos quais o esôfago foi acometido em 19, estômago em 42 e cólon em 7.

Na presente investigação procurou-se analisar a localização dos tumores em cada segmento estudado do tubo gastrointestinal, desde o esôfago até a segunda porção do duodeno, encontrando-se distribuição não uniforme no trato gastrointestinal. A maioria dos tumores encontrava-se no estômago (98), esôfago distal (50), e no duodeno (12), revelando a semelhança dos resultados com a literatura consultada ${ }^{51,36}$ e a importância da minuciosa avaliação proximal do trato gastrointestinal alto.

Este estudo apresentou comprometimento pela lesão, principalmente, na quarta e na segunda camadas, devido à maior prevalência de tumores tipos TEGI e leiomioma.

\section{Aspecto endoscópico}

A EDA tem sua importância na avaliação das lesões subepiteliais, pois é o primeiro exame a fornecer imagem suspeita de TSE e, em algumas vezes, permite diferenciar CE e TI com a mudança de decúbito do paciente, ou com a insuflação do órgão ou mesmo caracterizando algumas lesões subepiteliais com base em certos achados endoscópicos (cor, consistência, mobilidade, "sinal do travesseiro"). Em particular a endoscopia apresentou alta sensibilidade para o diagnóstico de lipomas, baseado na ausência ou presença do "sinal do travesseiro", que consiste na permanência da depressão induzida na lesão pela pressão da pinça de biópsia. Dos oito casos de lipoma, a EDA foi sugestiva em sete, e contudo, a endoscopia não foi precisa no diagnóstico de outras lesões subepiteliais, e que confirma a necessidade da EE na avaliação destas lesões. 


\section{Aspecto ecoendoscópico}

$\mathrm{Na}$ literatura consultada os leiomiomas apresentaram-se como lesões hipoecóicas, não heterogêneas e atingindo principalmente a $2^{\mathrm{a}}$ camada, TEGI como lesão hipoecóica, elíptica, na $2^{\mathrm{a}}$ ou $4^{\mathrm{a}}$ camada e os lipomas como lesão hiperecóica e depressível ${ }^{5,52,53,54}$.

Palazzo e col descreveram 15 pacientes com tumor de Abrikossof, que apresentava aspecto hipoecóico, com tamanho menor que $2 \mathrm{~cm}$ e situados na $2^{\mathrm{a}}$ ou $3^{\mathrm{a}}$ camada $^{(55)}$.

O TEGI apresentou-se de forma variada. De maneira geral, caracterizou-se como lesão hipoecóica, ovóide ou elíptica, pediculada ou multilobulada, situada na $2^{\mathrm{a}}$ ou $4^{\mathrm{a}}$ camada. Os leiomiomas apresentaram aspecto ecográfico semelhante ao dos TEGI e foram descritos como lesões hipoecóicas, contíguas à $2^{\mathrm{a}}$ ou $4^{\mathrm{a}}$ camada da parede do TGI, como na literatura $^{52,53,54}$. Nos lipomas a EE foi útil quando o aspecto endoscópico não foi característico, sendo identificados como lesões, em geral, solitárias, hiperecóicas, homogêneas, originadas na submucosa ( $3^{\mathrm{a}}$ camada). À EE as varizes apresentaram-se como estruturas tubulares anecóicas de aspecto serpiginoso, com contorno bem definido e os cistos foram visualizados como lesões anecóicas, arredondadas ou ovóides, com contorno bem definido

Na presente casuística, os aspectos encontrados foram semelhantes aos descritos na literatura $5,52,53,54,55$.

O exame ecoendoscópico permite definir se a lesão é intra ou extramural; se a lesão for intramural, identifica-se a camada de origem e estuda-se ecogenicidade, contornos, limites e características. O conjunto destas informações fornece o diagnóstico diferencial e permite uma melhor elucidação etiológica.

A ecoendoscopia é um método de imagem que baseando-se em características macroscópicas, permite inferir o diagnóstico diferencial das lesões intramurais. 


\section{Análise comparativa entre EDA e EE no diagnóstico presuntivo dos TSE}

Nas compressões extrínsecas a EDA apresentou sensibilidade, especificidade e acurácia baixas, com valores menores de 50\%; isto é decorrente do fato da EDA revelar poucos verdadeiro-positivos (9/23) e nenhum verdadeiro-negativo, mostrando que não há associação entre a EDA e a histologia, o que define a EDA não ser um bom exame para o diagnóstico presuntivo. Resultados semelhantes foram observados, com o uso da EDA na avaliação de CE, com o trabalho de Caletti e col. ${ }^{63}$ que demonstraram sensibilidade e especificidade de 47 e $36 \%$ respectivamente.

Os resultados da EE apresentaram sensibilidade, especificidade e acurácia próximas de $100 \%$ dos 22 casos com diagnóstico histológico de CE; a EE foi positiva em 21, principalmente com uso de ecoendoscópios de alta freqüência, pois permite melhor avaliação das estruturas comprovando-se como um bom exame para o diagnóstico presuntivo das compressões extrínsecas.

$\mathrm{O}$ valor de $\mathrm{p}=0,08$ corresponde à ausência de associação entre EE e histologia, porém com valor muito próximo ao ponto de corte, diferente da EDA.

Gress F e col. ${ }^{9}$ apresentaram dados de um estudo de concordância da interpretação ecoendoscópica dos TSE usando o índice de Kappa, conforme pôde-se observar na tabela 1, mostrando que na avaliação de CE o índice é de 0,94, ou seja, excelente.

A indicação da EE para o diagnóstico específico do TSE também permite o estudo ecográfico transmural detalhado do trato gastrointestinal alto e baixo.

A EE representa um meio diagnóstico de alto nível técnico para avaliação dos TSE. Com este exame pôde ser feito um estudo criterioso do tamanho, da profundidade e da extensão da lesão. A primeira informação fornecida pela imagem é a relação da lesão com as camadas da parede do trato gastrointestinal, que permite a exclusão das compressões extrínsecas e confirmação de TI. 
$\mathrm{Na}$ avaliação dos tumores intramurais os resultados da EDA apresentaram sensibilidade e acurácia altas, $87 \%$ e $86 \%$ respectivamente, ou seja, tem alta capacidade em detectar algo que existe, neste caso, os TI, porém com uma baixa especificidade (50\%); o valor de $\mathrm{p}=0,25$ demonstra que não houve associação entre EDA e histologia na avaliação destes tumores.

Estudos anteriores demonstraram que, mesmo quando o endoscopista suspeita da lesão subepitelial ser intramural, o tumor pode ser extramural em $30 \%$ dos $\operatorname{casos}^{46,50}$.

A EE, como na literatura ${ }^{48}$, apresentou-se como um meio diagnóstico essencial para a avaliação dos TI, com sensibilidade, especificidade e acurácia em torno de $100 \%$.

Rosch e $\operatorname{col}^{46}$, estudando 113 pacientes e avaliando as paredes do TGI com a EE, apresentou sensibilidade e especificidade de 99 e $97 \%$ respectivamente para o diagnóstico de TI.

Um dado conflitante relacionou-se aos valores do índice de Kappa. Gress e col. demonstraram fraca concordância da interpretação ecoendoscópica com o diagnóstico histológico para lesões como o leiomioma e TEGI, diferentemente do presente estudo no qual houve concordância nos 94 casos de TEGI e em todos os 22 leiomiomas. Esta concordância no diagnóstico deve-se, principalmente, ao fato das lesões intramurais apresentarem características próprias de ecogenicidade e localização.

O valor encontrado de $\mathrm{p}=0,0003$ mostrou uma excelente associação entre EE e histologia no diagnóstico das lesões intramurais; dos 151 pacientes com confirmação histológica de TI, a EE sugeriu este diagnóstico em 150 casos.

Rosch e col. ${ }^{46}$ avaliaram todo o trato digestivo com EE e mostraram um valor de p=0,010 da associação do diagnóstico histológico com o exame ecosonográfico nos tumores intramurais, deste modo apresentando semelhança com a presente pesquisa e divergências quanto aos índices de Kappa. 
A ultra-sonografia endoscópica é um método diagnóstico que mostra todas as camadas da parede do órgão, e com isso confirma o caráter intraparietal da lesão, diferenciando-a da CE e fornecendo várias características da lesão.

Observa-se com isso, que é justificado o uso da ecoendoscopia como método de avaliação complementar na diferenciação entre lesão intramural e compressão extrínseca.

$\mathrm{Na}$ análise global, os resultados mostram que a endoscopia digestiva alta apresenta sensibilidade e especificidade baixas para diagnosticar compressão extrínseca e uma alta sensibilidade e baixa especificidade para diagnosticar lesão intramural. A ecoendoscopia aumenta todos estes valores na avaliação dos tumores subepiteliais, permitindo realizar um diagnóstico diferencial destas lesões, fornecer com precisão a localização do tumor e suas características, além de permitir biópsias dirigidas. 
ConCLUSÕES 


\section{CONCLUSÕES}

A avaliação entre endoscopia digestiva alta e ecoendoscopia no diagnóstico dos tumores subepiteliais do esôfago, estômago e duodeno, nas condições em que foi realizada esta pesquisa, permite concluir:

A endoscopia digestiva é um bom exame para diagnosticar a presença de tumores subepiteliais do trato digestivo, mas tem fraco desempenho em identificar o tipo específico do tumor, tanto das compressões extrínsecas como dos tumores intramurais. Por outro lado, a ecoendoscopia é um bom exame para o diagnóstico das compressões extrínsecas e um excelente exame para o diagnóstico de tumores intramurais.

A ecoendoscopia pode diagnosticar com precisão a camada na qual se encontra a lesão, permite o diagnóstico diferencial dos tumores intramurais, além de obter material para exame histológico e/ou citológico. 
$\boldsymbol{R}_{\text {EFERÊNCIAS BIBLIOGRÁFICAS }}$ 


\section{REFERÊNCIAS BIBLIOGRÁFICAS}

1. Feczko PJ, Halpert RD, Ackerman LV. Gastric polyps: radiological evaluation and clinical significance. Radiology 1985;155(3):581-4.

2. Bolandi C, Savides T. Tumors of the stomach. In: Yamada T, Alpers D, Laine L, Owyang C, Powell D, editors. Textbook of Gastroenterology. 3a ed. United States of America: Lippincott Williams \& Wilkins; 1991. p. 1500-29.

3. Chung R. Benign and malignant tumors of the stomach. In: Sivak JM, Schleutermann DA, editors. Gastroenterology Endoscopy. 2nd ed: W. B. Saunders Company; 2000. p. 671-702.

4. Polkowski M, Butruk E. Submucosal lesions. Gastrointest Endosc Clin N Am 2005;15(1):33-54, viii.

5. Chak A. EUS in submucosal tumors. Gastrointest Endosc 2002;56(4 Suppl):S43-8.

6. Ardengh JC, Paulo GA. Endossonografia. In: Castro LP, Coelho LGV, editors. Gastroenterologia. 1 ed. ed. Rio de Janeiro: MEDSI; 2004. p. 2911-40.

7. Boyce GA, Sivak MV, Jr., Rosch T, Classen M, Fleischer DE, Boyce HW, Jr., et al. Evaluation of submucosal upper gastrointestinal tract lesions by endoscopic ultrasound. Gastrointest Endosc 1991;37(4):449-54.

8. Buscarini E, Stasi MD, Rossi S, Silva M, Giangregorio F, Adriano Z, et al. Endosonographic diagnosis of submucosal upper gastrointestinal tract lesions and large fold gastropathies by catheter ultrasound probe. Gastrointest Endosc 1999;49(2):184-91.

9. Gress F, Schmitt C, Savides T, Faigel DO, Catalano M, Wassef W, et al. Interobserver agreement for EUS in the evaluation and diagnosis of submucosal masses. Gastrointest Endosc 2001;53(1):71-6.

10. Lambert R, Caletti G, Cho E, Chang KJ, Fusaroli P, Feussner H, et al. International Workshop on the clinical impact of endoscopic ultrasound in gastroenterology. Endoscopy 2000;32(7):549-84. 
11. Lightdale CJ. Indications, contraindications, and complications of endoscopic ultrasonography. Gastrointest Endosc 1996;43(2 pt 2):S15-9

12. Jochem RJ, Reading CC, Dozois RR, Carpenter HA, Wolff BG, Chraboneau JW, Endorectal ultrasonographic staging of retal carcinoma. Mayo clinic Proc 1990; 65:1571-7.

13. Chonan A, Mochizuki F, Ando M. Endosonography. In: Margulis AR, Baert AL, Brandy WL, eds. Modern imaging of the alimentary tube. $1^{\text {st }}$ ed New York, NY: Springer-Verlag, 1998:62-70.

14. Botet JF, Gerdes H. Endoscopic ultrasound of the gastrointestinal tract. In: Kane RA, Donley S, eds. Intraoperative, laparoscopic and endoluminal ultrasound. $1^{\text {st }}$ ed. Philadelphia, PA: Churchill Livingstone, 1999:169-83

15. Silverstein FE, Martin RW, Kimmey MB, Jiranek GC, Franklin DW, Proctor A. Experimental Evaluation of an endoscopic ultrasound probe: in vitro and in vivo canine studies. Gastroenterology 1989;96:1058-62

16. Kimmey MB, Martin RW, Silverstein FE, Endoscopic ultrasound probes. Gastrointest Endosc 1990; 36(2 Suppl):S40-6.

17. Bhutani, M., et al., Endoscopic ultrasound guided fine needle aspiration of malignant pancreatic lesions. Endoscopy, 1997.29: p.854-858.

18. Chang, K., P. Nguyen, and R. Erickson The clinical utility of endoscopic ultrasound guided fine-needle aspiration in the diagnosis and staging of pancreatic carcinoma. Gastrointestinal Endoscopy, 1997, 45: p 387-393.

19. Gress, F., et al., Endoscopic ultrasonography, fine-needle aspiration biopsy guided by endoscopic ultrasonography,. A comparison study. Ann Intern Med, 1997, 127: p. 604-612.

20. Ardengh JC, Pauphilet C, Ganc AJ. Ecoendoscopia uma nova opção propedêutica. GED 1993;12(1):32-6.

21. Catalano MF. Normal structures on endoscopic ultrasonography: visualization measurement data and interobserver variation. Gastrointest Endosc Clin N Am 1995;5(3):475-86. 
22. Vilmann P, Hancke S. Endoscopic ultrasound scanning of the upper gastrointestinal tract using a curved linear array transducer: "the linear anatomy". Gastrointest Endosc Clin N Am 1995;5(3):507-21.

23. Hawes RH. Normal endosonographic findings. Gastrointest Endosc 1996;43(2 Pt 2):S6-10.

24. O'Toole D, Palazzo L, Arotcarena R, Dancour A, Aubert A, Hammel P, et al. Assessment of complications of EUS-guided fine-needle aspiration. Gastrointest Endosc 2001;53(4):470-4.

25. Grant EG. Seção 3: Abdominal - Peritonial. Fígado. In: Mittelstaedt CA, editor. Ultra-sonografia geral. Rio de Janeiro: Revinter; 2000. p. 173 -248.

26. Standards and Guidelines for Performance of the Abdominal and Retroperitoneal Examination: American Institute of Ultrasound in Medicine; 1990.

27. Kane RA. Sonographic anatomy of the liver. Semin Ultrasound CT MR 1981;2:190.

28. Mittelstaedt CA. Seção 3: Abdominal - Peritonial. Sistema biliar. In: Mittelstaedt CA, editor. Ultra-sonografia geral. Rio de Janeiro: Revinter; 2000. p. 249-370.

29. Parulekar SG. Evaluation of the prone view for cholecystosonography. J Ultrasound Med 1986;5(11):617-24.

30. Kane RA. Ultrasonography anatomy of the liver and biliary tree. Semin Ultrasound CT MR 1980;1:87.

31 Cooperberg PL. Real-time ultrasonography of the gallbladder. In: Winsberg F, Cooperberg PL, editors. Clinics and Diagnostic Ultrasound: Real -time Ultrasonography. New York: Churchill Livingstone; 1982. p. 49.

32. Callen PW, Filly RA. Ultrasonographic localization of the gallbladder. Radiology 1979;133(3 Pt 1):687-91. 
33. Laing FC, Jeffrey RB. The pseudo-dilated common bile duct: ultrasonographic appearance created by the gallbladder neck. Radiology 1980;135(2):405-7.

34. Birnholz JC. Population survey: ultrasonic cholecystography. Gastrointest Radiol 1982;7(2):165-7.

35. Ueyama T, Guo KJ, Hashimoto H, Daimaru Y, Enjoji M. A clinicopathologic and immunohistochemical study of gastrointestinal stromal tumors. Cancer 1992;69(4):947-55.

36. Morrissey K, Cho ES, Gray GF, Jr., Thorbjarnarson B. Muscular tumors of the stomach: clinical and pathological study of 113 cases. Ann Surg 1973;178(2):148-55.

37. Shiu MH, Farr GH, Papachristou DN, Hajdu SI. Myosarcomas of the stomach: natural history, prognostic factors and management. Cancer 1982;49(1):177-87.

38. Nickl N. Endoscopic approach to gastrointestinal stromal tumors. Gastrointest Endosc Clin N Am 2005;15(3):455-66, viii.

39. Palazzo L, Landi B, Cellier C, Cuillerier E, Roseau G, Barbier JP. Endosonographic features predictive of benign and malignant gastrointestinal stromal cell tumours. Gut 2000;46(1):88-92.

40. Nickl NJ. Gastrointestinal stromal tumors: new progress, new questions. Curr Opin Gastroenterol 2004;20(5):482-7.

41. Pierie JP, Choudry U, Muzikansky A, Yeap BY, Souba WW, Ott MJ. The effect of surgery and grade on outcome of gastrointestinal stromal tumors. Arch Surg 2001;136(4):383-9.

42. Fletcher CD, Berman JJ, Corless C, Gorstein F, Lasota J, Longley BJ, et al. Diagnosis of gastrointestinal stromal tumors: A consensus approach. Hum Pathol 2002;33(5):459-65.

43. Ando N, Goto H, Niwa Y, Hirooka Y, Ohmiya N, Nagasaka T, et al. The diagnosis of GI stromal tumors with EUS-guided fine needle aspiration with immunohistochemical analysis. Gastrointest Endosc 2002;55(1):37-43. 
44. Van Dam J, Sivak MV. In: Van Dam J, Sivak MV, editors. Gastrointestinal endosonography. 1st ed. Philadelphia: Saunders Co. W.B.; 1999.

45. Ardengh JC, de Paulo GA, Lourenço KG, Barbosa CFM. GIST: The role of endoscopic ultrasound (EUS) with fine needle aspiration (EUS-FNA) in the differential diagnosis of leiomiomas using c-KIT immunohistochemistry. In: World Congress of Gastroenterology, editor. Montreal: OMED; 2005.

46. Rosch T, Lorenz R, Dancygier H, von Wickert A, Classen M. Endosonographic diagnosis of submucosal gastrointestinal tract tumors. Scand J Gastroenterol $1992 ; 27(1): 1-8$.

47. Yasuda K, Cho E, Nakajima M, Kawai K. Diagnosis of submucosal lesions of the gastrointestinal tract by endoscopic ultrasonography. Gastrointest Endosc 1990;36(2 Suppl):S17-20.

48. Brand B, Oesterhelweg L, Binmoeller KF, Sriram PV, Bohnacker S, Seewald S, et al. Impact of endoscopic ultrasound for evaluation of submucosal lesions in gastrointestinal tract. Dig Liver Dis 2002;34(4):290-7.

49. Norberto L, Urso E, Angriman I, Ranzato R, Erroi F, Marino S, et al. Yttriumaluminum-garnet laser therapy of esophageal granular cell tumor. Surg Endosc 2002;16(2):361-2.

50. Motoo Y, Okai T, Ohta H, Satomura Y, Watanabe H, Yamakawa O, et al. Endoscopic ultrasonography in the diagnosis of extraluminal compressions mimicking gastric submucosal tumors. Endoscopy 1994;26(2):239-42.

51. Fusaroli P, Khodadadian R, Togliani T, Caletti G. Gastrointestinal stromal tumors: long-term follow-up by EUS up to 13 years. Gastrointest Endosc 2002; 55(5):AB252.

52. Palazzo L, Landi B, Cellier C, Cuillerier E, Roseau G, Barbier JP. Endosonographic features predictive of benign and malignant gastrointestinal stromal cell tumours. Gut 2000;46(1):88-92.

53. Van Stolk RU. Subepithelial lesions. In: Van Dam J, Sivak MV, editors. Gastrointestinal Endosography: W.B.Saunders Company; 1999. p. 156.

54. Ishikawa N, Fuchigami T, Kikuchi Y, Kobayashi H, Sakai Y, Nakanishi M, et al. EUS for gastric lymphangioma. Gastrointest Endosc 2000;52(6):798-800. 
55. Palazzo L, Landi B, Cellier C, Roseau G, Chaussade S, Couturier D, et al. Endosonographic features of esophageal granular cell tumors. Endoscopy 1997;29(9):850-3.

56. Mazur MT, Clark HB. Gastric stromal tumors. Reappraisal of histogenesis. Am J Surg Pathol 1983;7(6):507-19.

57. Miettinen M, Lasota J. Gastrointestinal stromal tumors--definition, clinical, histological, immunohistochemical, and molecular genetic features and differential diagnosis. Virchows Arch 2001;438(1):1-12.

58. Fletcher CD, Berman JJ, Corless C, Gorstein F, Lasota J, Longley BJ, et al. Diagnosis of gastrointestinal stromal tumors: A consensus approach. Hum Pathol 2002;33(5):459-65.

59. Hunt GC, Rader AE, Faigel DO. A comparison of EUS features between CD-117 positive GI stromal tumors and CD-117 negative GI spindle cell tumors. Gastrointest Endosc 2003;57(4):469-74.

60. Newman PL, Wadden C, Fletcher CD. Gastrointestinal stromal tumours: correlation of immunophenotype with clinicopathological features. J Pathol 1991;164(2):107-17.

61. Hwang JH, Kimmey MB. The Incidental gastrointestinal subepithelial mass. Gastroenterology 2004;126:301-7.

62. Boyce GA, Sivak MV Jr, Roch T, Classen M, Fleischer DE et al. Evaluation of submucosal gastrointestinal tract lesions by endoscopic ultrasound. Gastrointestinal Endosc 1991;37:449-54.

63. Caletti G, Zani L, Brocchi E, Rollo V, Barbara L. Endoscopic ultrasonography in the diagnosis of gastric submucosal tumor. Gastrointest Endosc 1989;35:413-8. 
ANEXO 


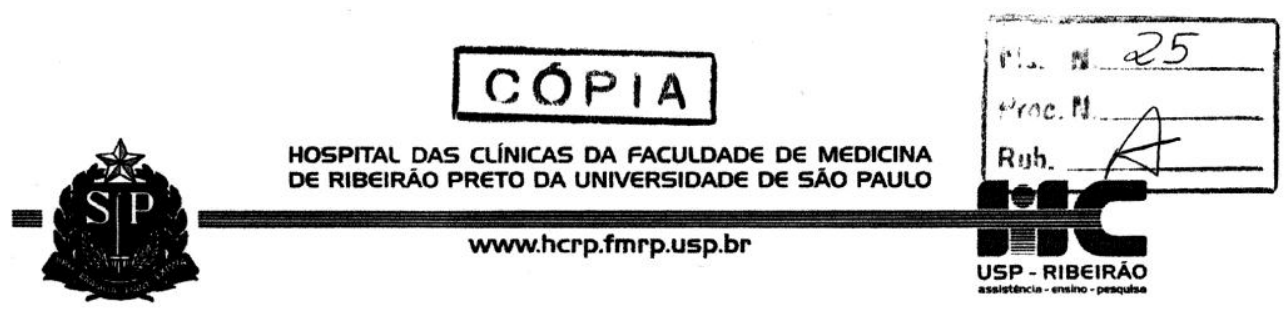

Ribeirão Preto, 03 de janeiro de 2008.

Oficio $n^{\circ} .21 / 2008$

CEP/MGV

Prezado Doutor,

O trabalho intitulado "ESTUDO COMParatro
ENTRE ENDOSCOPIA DIGESTIVA(EDA) E ECOENDOSCOPIA(EE) NA
AVALIAÇĀO DOS TUMORES SÓLIDOS SUBEPITELIAIS

Gastrintestrnars", foi analisado pelo Comitê de Ética em Pesquisa e APROVADO “AD REFERENDUM" em 03/01/2008, de acordo com o Processo HCRP n 9012/2007.

Lembramos que devem ser encaminhados a este CEP relatórios parciais e relatório final da pesquisa.

Atenciosamente.

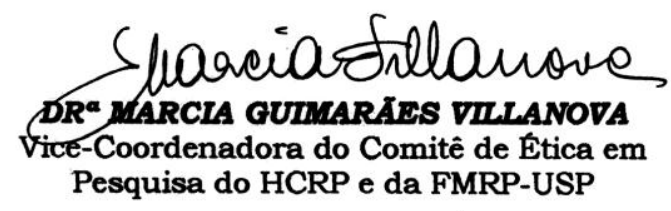

Ilustrissimo Senhor

DR. SPENCER VAICIUNAS

PROF. DR. REGINALDO CENEVIVA (Orientador)

Depto. de Cirurgia e Anatomia 